\title{
Chemotherapy in NEN: still has a role?
}

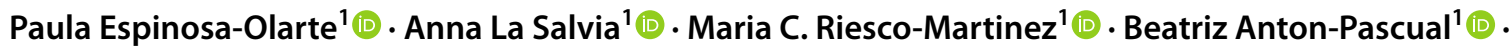 \\ Rocio Garcia-Carbonero ${ }^{1}$ (i)
}

Accepted: 23 February 2021 / Published online: 11 April 2021

(c) The Author(s) 2021

\begin{abstract}
Neuroendocrine neoplasms (NENs) comprise a broad spectrum of tumors with widely variable biological and clinical behavior. Primary tumor site, extent of disease, tumor differentiation and expression of so matostatin receptors, proliferation and growth rates are the major prognostic factors that determine the therapeutic strategy. Treatment options for advanced disease have considerably expanded in recent years, particularly for well differentiated tumors (NETs). Novel drugs approved over the past decade in this context include somatostatin analogues and ${ }^{177} \mathrm{Lu}$-oxodotreotide for somatostatin-receptor-positive gastroenteropancreatic (GEP) NETs, sunitinib for pancreatic NETs (P-NETs), and everolimus for P-NETs and non-functioning lung or gastrointestinal NETs. Nevertheless, chemotherapy remains an essential component of the treatment armamentarium of patients with NENs, particularly of patients with P-NETs or those with bulky, symptomatic or rapidly progressive tumors (generally G3 or high-G2 NENs). In this manuscript we will comprehensively review available evidence related to the use of chemotherapy in lung and GEP NENs and will critically discuss its role in the treatment algorithm of this family of neoplasms.
\end{abstract}

\begin{tabular}{|c|c|}
\hline \multicolumn{2}{|c|}{ Abbreviations } \\
\hline 5-FU & 5- Fluorouracil \\
\hline AEs & Adverse events \\
\hline BEVA & Bevacizumab \\
\hline BSC & Best supportive care \\
\hline CAP & Capecitabine \\
\hline CAPOX & Capecitabine and oxaliplatin \\
\hline CAPOXIRI & Capecitabine, oxaliplatin and irinotecan \\
\hline CAPTEM & Capecitabine and temozolomide \\
\hline CBDCA & Carboplatin \\
\hline CDDP & Cisplatin \\
\hline CTX & Cyclophosphamide \\
\hline CTZ & Chlorozotocin \\
\hline CYP450 & Cytochrome P450 \\
\hline DCR & Disease control rate \\
\hline DOXO & Doxorubicin \\
\hline DTIC & Dacarbazine \\
\hline ECOG & Eastern Cooperative Group \\
\hline EP-NETs & Extra-pancreatic neuroendocrine tumors \\
\hline EPI & Epirubicin \\
\hline EVE & Everolimus \\
\hline
\end{tabular}

Rocio Garcia-Carbonero rgcarbonero@gmail.com

1 Oncology Department, Hospital Universitario, 12 de Octubre, Imas12, UCM, Madrid, Spain

$\begin{array}{ll}\text { EVO } & \text { Evofosfamide } \\ \text { FFCD } & \text { Fédération Francophonede Cancérologie } \\ & \text { Digestive } \\ \text { FOLFIRI } & \text { 5-FU and Irinotecan } \\ \text { FOLFOX } & \text { 5-FU and oxaliplatin } \\ \text { GEMOX } & \text { Gemcitabine and oxaliplatin } \\ \text { GEP } & \text { Gastroenteropancreatic } \\ \text { GI } & \text { Gastrointestinal } \\ \text { HB } & \text { Hepatobiliary } \\ \text { HN } & \text { Head and neck } \\ \text { IP } & \text { Irinotecan and platinum } \\ \text { IRI } & \text { Irinotecan } \\ \text { L } & \text { Lung } \\ \text { LAN } & \text { Lanreotide } \\ \text { LDH } & \text { Lactate dehydrogenase } \\ \text { m } & \text { Months } \\ \text { MANEC } & \text { Mixed adenoneuroendocrine carcinoma } \\ \text { MGMT } & \text { O-6-methylguanine-DNA methyltransferase } \\ \text { MINEN } & \text { Mixed neuroendocrine non-neuroendocrine } \\ & \text { neoplasia } \\ \text { MSI } & \text { Microsatellite instability } \\ \text { MTIC } & \text { 3-Methyl-(triazen-1-yl) } \\ \text { NECs } & \text { imidazole-4-carboxamide } \\ \text { NENs } & \text { Neuroendocrine carcinomas } \\ \text { NETs } & \text { Neuroendocrine neoplasias } \\ & \end{array}$




$\begin{array}{ll}\text { NR } & \text { Not reported } \\ \text { Ns } & \text { Non significant } \\ \text { NTR } & \text { National tumor registry } \\ \text { NTRK } & \text { Neurotrophic receptor tyrosine kinase 1 } \\ \text { OCT } & \text { Octreotide } \\ \text { OR } & \text { Odds ratio } \\ \text { ORR } & \text { Objective response rate } \\ \text { OS } & \text { Overall survival } \\ \text { P-NETs } & \text { Pancreatic neuroendocrine tumors } \\ \text { PARP } & \text { Poly(ADP)-ribose polymerase } \\ \text { PAZO } & \text { Pazopanib } \\ \text { PDGFR } & \text { Platelet derived growth factor receptor } \\ \text { PFS } & \text { Progression-free survival } \\ \text { PRRT } & \text { Peptide receptor radionuclide therapy } \\ \text { PS } & \text { Performance status } \\ \text { Rb } & \text { Retinoblastoma } \\ \text { RENATEN } & \text { Groupe d'étude des Tumeurs Endocrines } \\ & \text { [GTE] } \\ \text { RGETNE } & \text { Registro del grupo español de tumores } \\ & \text { neuroendocrinos } \\ \text { RR } & \text { Response rate } \\ \text { SCLC } & \text { Small cell lung cáncer } \\ \text { STZ } & \text { Streptozocin } \\ \text { SUN } & \text { Sunitinib } \\ \text { TEM } & \text { Temozolomide } \\ \text { TMB } & \text { Tumor mutational burden } \\ \text { TTP } & \text { Time to tumor progression } \\ \text { U } & \text { Unknown } \\ \text { VEGF } & \text { Vascular endothelial growth factor } \\ \text { VINC } & \text { Vincristine } \\ \text { VP-16 } & \text { Etoposide } \\ \text { XELOX } & \text { Capecitabine and oxaliplatin } \\ \text { y } & \text { Year } \\ & \end{array}$

\section{Introduction}

Neuroendocrine neoplasias (NENs) are a heterogeneous family of malignancies of wide anatomic distribution, as they arise from neuroendocrine cells distributed throughout the body forming glands or as part of the diffuse neuroendocrine system. The majority of NENs are from gastroenteropancreatic (GEP) $(66 \%)$ and bronchopulmonary origin $(31 \%)$, although they may develop in any organ. Their incidence has significantly increased over the past 4 decades, from 1,09 (1973) to 6,98 (2012) new cases per 100.000 inhabitants per year, as well as their prevalence (from $0.006 \%$ (1993) to $0.048 \%$ (2012) 20-year limited-duration prevalence) [1]. The raise in incidence has been observed across all tumor sites, stages and grades, likely due to improved diagnostic techniques and greater clinical awareness. Survival has also improved over time as a consequence of earlier detection and the therapeutic advances achieved over the past decades
[1]. GEP-NENs are classified based on morphology and proliferation rate in well differentiated neuroendocrine tumors (NETs) (G1 to G3) or poorly differentiated large or small cell neuroendocrine carcinomas (NECs) (all G3) [2]. LungNENs are classified based on morphology and mitotic count as well differentiated typical or atypical carcinoids, or poorly differentiated large or small cell NECs [3]. Tumor differentiation in both GEP and lung NENs reflect two major biologically and genetically distinct entities with very different clinical behavior, including response to available treatments. Primary tumor site, extent of disease, tumor expression of somatostatin receptors, proliferation and growth rates are also major prognostic factors that shall be taken into account to define treatment strategy.

Treatment options for advanced disease have considerably expanded in recent years, particularly for NETs [4]. Most remarkable drugs recently incorporated to the treatment armamentarium include somatostatin analogues (lanreotide, octreotide) for G1 or low G2 gastroenteropancreatic (GEP) NETs [5, 6], sunitinib for pancreatic NETs (P-NETs) [7], everolimus for non-functioning lung or gastrointestinal NETs (L-or GI-NETs) and P-NETs $[8,9]$, and ${ }^{177} \mathrm{Lu}-$ oxodotreotide for somatostatin-receptor-positive GEP-NETs [10]. Despite these unquestionable steps forward, options are still rather limited, and chemotherapy remains an essential component of the treatment strategy of patients with NENs, particularly for those with bulky, symptomatic or rapidly progressive tumors (generally G3 or high-G2 NENs). In the setting of well differentiated NENs, chemotherapy is primarily indicated in tumors of pancreatic origin (P-NETs), whereas its use in L- or GI-NETs shall be reserved for selected patients who have failed other more effective therapeutic options.

In this manuscript we will critically review available evidence for the use of chemotherapy in lung and GEP NENs and will discuss its current role in the treatment algorithm of this family of neoplasms (Fig. 1).

\subsection{Role of chemotherapy in neuroendocrine tumors}

Chemotherapy in NENs initially focused on the treatment of islet cell carcinomas, that is P-NETs per current terminology, following the discovery of the alkylating agent streptozotocin (STZ), a glucose analogue isolated from Streptomyces achromogenes that was found to be particularly toxic to the $\beta$-cell of the pancreas via GLUT2 transporter uptake. The first randomized trials date from the $80 \mathrm{~s}$ ' and provided the first evidence of drug antitumor activity in NETs, leading to FDA-approval of STZ for the treatment of advanced islet cell carcinoma. This is the first drug and solely cytotoxic agent ever approved in the field of NENs. Subsequent trials tested different classical cytotoxic regimens, mainly 


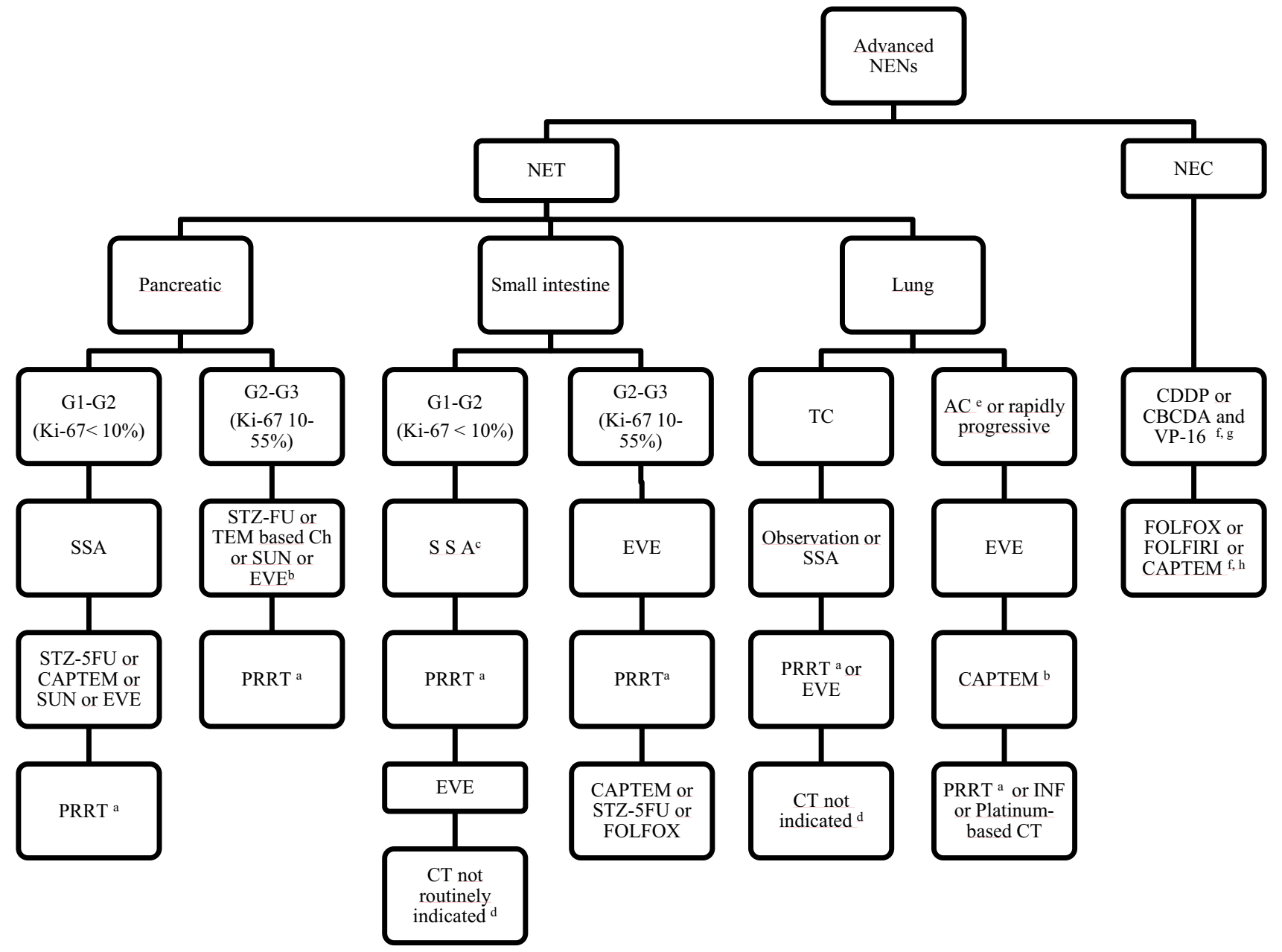

Fig. 1 Treatment algorithm of advanced NENs. AC, atypical carcinoid; CAPTEM, capecitabine-temozolomide; CDDP, cisplatin; CBCDA, carboplatin; CT, chemotherapy; EVE, everolimus; FOLFIRI, 5-fluorouracil and irinotecan; FOLFOX, 5-fluorouracil and oxaliplatin; INF, interferon-alfa; NENs, neuroendocrine neoplasias; NET, neuroendocrine tumor; NEC, neuroendocrine carcinoma; PRRT, peptide receptor radionucleotide therapy; SSA, somatostatine analogues; STZ-5FU, streptozocin-5 Fluorouracile; SUN, sunitinib;TC, typical carcinoid; VP-16, etoposide. ${ }^{\mathrm{a}} \mathrm{In}$ somatostatin-receptor imaging positive tumors and/or refractory hormonal síndrome. ${ }^{\mathrm{b}} \mathrm{Chemotherapy} \mathrm{pre-}$ ferred upfront over targeted agents in G3 NETs. ${ }^{c}$ Watch and wait may

based in alkylating agents, antimetabolites and anthracyclines. These trials globally demonstrated greater efficacy of chemotherapy in P-NETs than in NETs from lung or GI origin. However, results of these trials are not easy to place in the context of current standards of care, as methods to assess response were less rigorous and standardized, tumor classification was exclusively based on morphology and did not address relevant prognostic features such as the proliferation rate, and study populations were often underpowered and included a wide range of non-stratified primary tumor sites, except for those specifically devoted to P-NETs. Consequently, evidence will be discussed within two major be considered in G1 very indolent tumors, particularly in older or frail patients. ${ }^{\mathrm{d}}$ CAPTEM may be considered after progression to all available treatments in selected patients with good PS and rapidly progress-

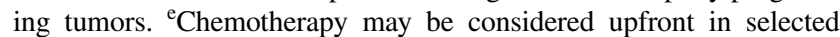
patients (rapidly progressing tumors, Ki-67>20\%). ${ }^{\mathrm{f}}$ Enrollement in clinical trials is recommended if available. ${ }^{g}$ Carboplatin is preferred over cisplatin due to its more favorable toxicity profile. ${ }^{\mathrm{h}}$ The treatment choice should be based on response to prior therapy, toxicity profile, residual toxicity from prior chemotherapy (i.e. neurotoxicity) and patient's comorbidities and preferences (i.e. oral vs iv)

subgroups, P-NETs and extrapancreatic-NETs, as the design of most trials does not allow to extract specific recommendations for lung or different GI tumor sites.

\subsection{Pancreatic NETs}

Streptozocin (STZ) is an alkylating agent that was the first drug to demonstrate efficacy in NETs. A seminal randomized trial published by Moertel et al. in 1980 assessed STZ alone and in combination with 5-fluorouracil (5-FU) in patients with advanced islet cell carcinomas, where the combination showed significantly greater response rates (RR), 63 vs. $36 \%$, 
and a tendency to an improved survival (26 vs. 16 months) [11]. A second randomized phase III trial also conducted in patients with advanced P-NETs showed improved outcomes with the combination of STZ and doxorubicin (DOXO) as compared to STZ and 5-FU in terms of RR (69 vs. $45 \%$ ), time to tumor progression and overall survival (OS) (26 vs 17 months) [12]. Despite its superior efficacy, however, the use of the STZ-DOXO combination has been limited by its less favorable toxicity profile, particularly due to DOXOinduced cumulative cardiotoxicity and alopecia. It should be noted that RR in these trials were not assessed by current standardized RECIST criteria; they included clinical, biochemical and radiological responses, and are therefore not comparable to objective radiological response (ORR) reported in recent trials. Three-drug combinations such as STZ, capecitabine and cisplatin (CDDP) did not demonstrate greater efficacy compared to STZ-capecitabine doublet regimens while they were significantly more toxic [13]. The STZ-5-FU regimen has been also assessed in combination with bevacizumab, a humanized monoclonal antibody targeting the vascular endothelial growth factor (VEGF), in the phase II BETTER trial that included 34 patients with P-NETs. The disease control rate (DCR) confirmed by centralized review was $100 \%$ : 19 patients $(56 \%)$ achieved a partial response and $15(44 \%)$ had stable disease as best response. Median PFS was 23,7 months and the OS rate at 2 years was $88 \%$ [14].

Dacarbazine (DTIC) is a synthetic alkylator that must be metabolized by cytochrome P450 (CYP450) to form its active metabolite, 3-methyl-(triazen-1-yl)imidazole-4carboxamide (MTIC). The first prospective trial with DTIC at high doses in P-NETs was conducted by Ramanathan et al. [15] and reported an ORR of 33\% (50\% among the 28 chemonaïve patients), and a median OS of 19,3 months. Toxicity was not negligible, with G3-4 adverse events (AEs) documented in $30 \%$ of patients (mainly vomiting and hematological toxicity) and 2 toxic deaths (one septic shock and one myocardial infarction). Safety is improved at lower doses as seen in subsequent trials, and it should also be noted that supportive care for emesis and myelotoxicity has substantially improved since these trials were conducted. DTIC has also been tested in small prospective non-randomized trials in combination with 5-FU and epirubicin with ORRs (25-27\%) that did not seem to be greater than DTIC monotherapy, whereas the combination substantially increases toxicity [15-17].

Temozolomide (TEM) is an oral derivative of DTIC which has displaced it in the treatment of NETs. It is also a prodrug that is spontaneously hydrolyzed at physiological $\mathrm{pH}$ to MTIC. MTIC methylates DNA commonly at the N-7 or O-6 positions of guanine residues. This DNA damage is repaired by the O-6-methylguanine-DNA methyltransferase (MGMT) and epigenetic silencing of the MGMT gene render cells more sensitive to this agent. MGMT expression loss assessed by immunohistochemistry or MGMT promoter methylation assessed by PCR or pyrosequencing has been successfully used as a positive predictive biomarker for TEM efficacy in other solid tumors, although its value in NETs is controversial $[18,19]$. Other DNA repair systems involved in reverting TEM-induced DNA damage include the mismatch repair system and poly(ADP)-ribose polymerase (PARP) pathway, and tumors with defects in these pathways could potentially be more sensitive to TEM. TEM crosses the blood-brain barrier and its toxicity profile (mainly nausea, vomiting, fatigue and hematological toxicity) is easily manageable.

TEM was first explored in some small prospective studies in combination with different targeted agents including antiangiogenics (thalidomide, bevacizumab) and mTOR inhibitors (everolimus), that reported ORR of $30-45 \%$ [20-22]. Retrospective studies also suggested promising activity for the combination of TEM and capecitabine (CAP) with response rates of up to $70 \%[19,23-30]$. But the most solid evidence of TEM efficacy in P-NETs has been recently provided by the E2211 randomized phase II trial conducted by the ECOG-ACRIN Cancer Research Group [31]. This trial included 144 patients with advanced G1-2 P-NETs that were randomized to receive TEM alone or in combination with CAP (CAPTEM). Prior permitted therapies included somatostatin analogues (received by $53-54 \%$ of patients), everolimus (35-36\%) or sunitinib (11-13\%), but not chemotherapy. ORR was not significantly different among study arms (33 vs. $28 \%$ ), but CAPTEM demonstrated improved PFS (22,7 vs. 14,1 months, HR $0.58, \mathrm{P}=0.023)$ and $\mathrm{OS}$ (not reached vs. 38 months, HR $0.41, \mathrm{P}=0.012$ ) as compared to TEM monotherapy. Of note, a greater proportion of $\mathrm{G} 2$ tumors was observed in the TEM arm (55 vs. 32\%), although grade was not significantly associated with PFS nor OS, and the benefit in survival favoring CAPTEM was still significant after adjustment for grade. G3-4 AEs were more commonly encountered in the CAPTEM arm (44 vs. $22 \%, \mathrm{P}=0.007)$. Significantly increased treatment related G3-4 AEs in the CAPTEM arm were neutropenia (13 vs. $4 \%$ ), nausea ( 8 vs. $0 \%$ ), vomiting ( 8 vs. $0 \%$ ), diarrhea ( 8 vs. $0 \%$ ) and fatigue ( 8 vs. $1 \%$ ). Treatment in the E2211 trial was continued until disease progression or unacceptable toxicity to a maximum of 13 cycles, although the optimal treatment duration is a matter of debate $[32,33]$.

CAP and TEM are both radiosensitizer drugs that have been used to increase the activity of peptide receptor radionuclide therapy (PRRT). The combination demonstrated to be safe in advanced NET patients in a phase I/II trial [34]. Promising results have been reported for the combination of CAPTEM with ${ }^{177}$-Lu-Octreotate in a prospective study, showing an ORR of $80 \%$ in P-NETs [35]. Based on these encouraging results, the Australasian Gastrointestinal Trials 
Group (AGITG) designed the CONTROL NET Study, a Phase II randomized (2:1) exploratory study evaluating the activity of ${ }^{177} \mathrm{Lu}$-Octreotate peptide receptor radionuclide therapy (PRRT) and CAPTEM in 2 patient cohorts. The P-NET cohort was randomized (2:1) to receive PRRT and CAPTEM vs CAPTEM alone, and the midgut cohort was randomized to receive PRRT and CAPTEM vs PRRT alone. Preliminary results recently presented of the P-NET cohort $(\mathrm{N}=27)$ showed numerically higher ORR for the combination $(67$ vs. $33 \%$ ) with no clear PFS benefit (PFS rate at 1 year: 76 vs. $67 \%$ ), and at the expense of greater G3-4 toxicity, mainly hematological. Longer follow-up to 36 months is planned to see whether a PFS benefit is observed sufficient to warrant phase III evaluation. Further follow-up is also required to carefully assess bone marrow toxicity, specifically regarding the eventual development of myelodysplastic syndrome or acute myeloid leukemia, which may be notably increased when PRRT is administered with alkylating agents and is of particular concern [36]. A phase I trial has explored the combination of TEM with TAS102. TAS102 consists of trifluridine, a nucleoside analog, and tipiracil, a thymidine phosphorylase inhibitor that prevents rapid metabolism of trifluridine, increasing thereby its bioavailability. TAS102 is non-cross resistant with 5-fluorouracil and capecitabine and has a different toxicity profile. In this trial the combination was well tolerated and the most frequent EAs $\geq \mathrm{G} 3$ were hematological (33\% neutropenia, 27\% lymphopenia, 27\% thrombocytopenia. The $8 \%$ of evaluable patients [13] had partial response, and the disease control rate (DCR) was 92\%. Enrollment into the expansion cohort of patients with advanced G1-2 P-NETs is ongoing [37].

Other fluoropyrimidine-based regimens explored in P-NETs include different combinations with irinotecan or oxaliplatin. The FOLFIRI regimen (irinotecan and 5-FU as continuous infusion), widely used in colorectal cancer and other digestive malignancies, has been tested in a prospective French study that included 20 chemo-naïve P-NETs and reported an $80 \%$ progression-free rate at 6 months (primary endpoint). Nevertheless, only one partial response was observed and this regimen was not exempt of toxicity, with G3-4 adverse events observed in $80 \%$ of patients [38]. A phase II trial by Ducreux et al. that included a small number of pretreated P-NET patients $(\mathrm{N}=10)$ also reported limited efficacy of FOLFIRI (ORR of 10\%) [39]. Oxaliplatin-based regimens such as CAPOX, FOLFOX or GEMOX (Gemcitabine and oxaliplatin), have also demonstrated to be active in advanced NETs, even though they have been generally assessed as a second line treatment. The largest retrospective study of 78 patients with NETs from different origins treated with CAPOX, GEMOX or FOLFOX, including 36 P-NETs with a mean ki-67 index of $14,4 \%$, globally reported an ORR of 33\% [40]. Prospective trials with platinum-based therapy are scarce and include a small number of NETs of pancreatic origin [41-44]. The phase II trial of Bajetta et al. [43] included 40 NEN patients, 11 with P-NETs, that were treated with XELOX. The ORR for P-NETs was $27 \%$. Of note, in this trial the ORR was superior in NETs (30\%) than in NECs (23\%). The combination of FOLFOX with Bevacizumab and CAPOX with bevacizumab was tested in two phase II trials. 12 and 16 patients with P-NETs were included, showing an ORRs of 50\% and 19\%, respectively. About $90 \%$ of patients recruited in both trials were well differentiated tumors (NETs), and the combination showed an overall disease control rate (DCR) of $94 \%$ with FOLFOXBevacizumab and of $78 \%$ with CAPOX-Bevacizumab [44]. Regarding chemotherapy and antiangiogenic regimens, a novel interesting approach recently explored the administration of sunitinib (SUN), a tyrosine kinase inhibitor targeting VEGFR and PDGFR among others, with the hypoxiatargeting prodrug evofosfamide (EVO), formally called TH-302, that is a DNA alkylator selectively activated under hypoxic conditions the SUNEVO trial (GETNE-1408) [45]. This study included 17 chemonaïve G1-2 P-NETs. The study reached the planned threshold for efficacy in the first step of simon design, with an ORR of $18 \%$, but was terminated early due to excess toxicity (65\% developed treatmentrelated G3-4 AEs, mostly fatigue and neutropenia; $100 \%$ of patients required EVO dose reduction due to toxicity) and also as Merck decided not to continue EVO clinical development following negative pivotal studies in other tumors (pancreatic adenocarcinoma, soft tissue sarcomas).

In summary, based on available evidence from randomized trials we may conclude that STZ-5FU has demonstrated to be more effective than STZ monotherapy in P-NETs (greater RR and a trend towards improved survival), and STZ-DOXO to be more effective than STZ-FU (greater RR, TTP and OS), although STZ-5FU is most widely used as its toxicity profile is more suitable for long-term treatment. However, it should be noted that STZ has never been tested against placebo or best supportive care (BSC), and therefore its individual contribution to efficacy in this setting is difficult to discriminate. More recently, the ECOGACRIN E2211 study has demonstrated that both TEM and CAPTEM are able to achieve significant tumor shrinkage assessed per current standard criteria in one third of patients, which is a relevant endpoint in a subgroup of highrisk P-NETs, and CAPTEM significantly impacted on PFS and OS. This regimen is presently the most widely used as its toxicity profile is more favorable and its oral administration is more convenient for most patients. Nevertheless, as with STZ, TEM has been never tested against placebo or BSC in this setting, and to date no published trial has compared these regimens against each other or against other chemotherapy combinations (FOLFOX, FOLFIRI...). Chemotherapy has not been compared either with targeted agents, so the optimal sequence and integration with other 
therapeutic strategies is still a matter of debate. Some ongoing trials however are currently assessing these issues. The BETTER-2 trial (NCT03351296) randomized G1-3 P-NET patients to receive STZ-5-FU vs. CAPTEM, with or without Bevacizumab, in a two by two design; its primary endpoint is PFS [46]. Moreover, the SEQTOR study (NCT02246127) [47], comparing EVE with STZ-5FU the OCCLURANDOM trial (NCT02230176) [48], comparing SUN with 177LuOxodotreotide, or the COMPETE study (NCT03049189), [49], comparing EVE with 177Lu-Edotreotide, will further provide relevant information in the near future to help clinicians optimize the sequential use of available treatment options in P-NETs. These and other chemotherapy-based trials in P-NETs $[50,51]$ are summarized in Table 1.

\section{Key messages}

- Chemotherapy is primarily indicated in advanced NETs of pancreatic origin, and is recommended as upfront therapy in tumors with high proliferation rates, G2 in the upper range (Ki-67> 10\%) or G3 (Ki-67 > 20\%), particularly in patients with bulky or rapidly progressive disease.

- Randomized trials to date have never compared chemotherapy versus placebo or best supportive care or other treatment options (ie. targeted therapy or PRRT), and this limitation should be bared in mind to interpret treatment recommendations with caution.

- STZ has demonstrated efficacy in P-NETs especially when combined with DOXO or 5-FU The STZ-DOX combination is more effective but more toxic than STZ$5 \mathrm{FU}$, particularly regarding cardiotoxicity and alopecia, and thus STZ-5FU is generally preferred by most clinicians and patients.

- More recently, TEM has also demonstrated efficacy inPNETs, particularly in combination with CAP, and the oral CAPTEM regimen isbeing increasingly used due to improved patient's tolerance and convenience.

- Ongoing randomized trials comparing head-to-head both chemotherapy regimens (CAPTEM vs STZ-5FU), or chemotherapy versus targeted agents (i.e. everolimus), or other currently available treatment options to treat P-NETs (i.e. PRRT vs everolimus or sunitinib) shall help elucidate their relative efficacy and the optimal treatment sequence in these patient

\subsection{Extra-pancreatic NETs}

Chemotherapy plays overall a minor role in the treatment of well-differentiated NETs of non-pancreatic origin. The term extra-pancreatic NETs (EP-NETs) encompass a wide spectrum of tumors that include primarily gastrointestinal (GI) (esophago-gastric, biliary tract, small and large bowel) and lung NETs, but also feochromocytomasparagangliomas, medullary thyroid carcinomas, gynecological or urologic NETs, NETs of unknown primary and others. They are indeed a very heterogeneous group in terms of molecular background, prognosis, treatment options and likely responsiveness to different therapies, but they have been traditionally gathered together in clinical trials under the general term "carcinoid". There are very few tumor-site specifically dedicated chemotherapy trials, and therefore site-specific results are generally obtained as sub-analysis of small cohorts of patients with tumors from a particular anatomic origin included in these mixed trials. In this review we will try to provide site-specific information when possible, although this shall be interpreted with great caution as it generally refers to retrospective, unplanned subgroup analysis of small patient subpopulations.

The first randomized trial in carcinoids (EST 3272) was published by Moertel et al. in 1979. This study included 118 patients with metastatic carcinoid tumors of different primary sites ( 40 small bowel, 10 other GI sites, 7 pancreas, 17 lung and 18 of unknown primary) that were randomly allocated to receive STZ with cyclophosphamide (CTX) or with 5-FU, with a crossover design to single agent 5-FU or CTX upon disease progression [52]. RRs were $33 \%$ for patients in the STZ-5FU arm vs $26 \%$ for those treated with STZ-CTX. Of note, RR was significantly greater in patients with small bowel carcinoids (44 vs. $37 \%$, respectively), than in patients with lung tumors ( 29 vs. $0 \%$ ) or tumors of unknown primary ( 29 vs. $0 \%$ ). Two of 11 patients that crossed-over to 5-FU responded, but none of the 8 patients that crossed over to CTX did. There was no significant difference in survival between the two treatment arms, but survival did differ by primary tumor origin: 28.4 months for small bowel, 24.0 months for pancreas, 15.1 months for lung and 9.0 months for unknown primary. Subsequently, the EST 5275 compared the STZ-5FU regimen with DOXO monotherapy in 172 patients with progressive carcinoid tumors (61 small bowel, 18 other GI, 18 lung, 75 other or unknown) [53]. There were no significant differences among study arms in RR (22 vs. $21 \%$ ) or survival (median of 16 vs. 12 months). Thirty-three patients who failed STZ-5FU crossed over to DOXO achieving a RR of $18 \%$. Thirty-five patients who failed DOXO and crossed over to STZ-5FU achieved a RR of $29 \%$. Both regimens have therefore similar activity in carcinoid tumors and they mainly differ in their toxicity profiles. Based on the results of these 2 trials, the Eastern Cooperative Group (ECOG) designed the E1281 study, a phase II-III trial that randomized 176 patients with advanced carcinoid tumors (43 small bowel, 12 cecum/ rectum, 8 pancreas, 22 lung, and 78 other or unknown) to receive STZ-5FU vs DOXO-5FU [54]. Sixty-one patients were treated with DTIC upon disease progression. There were no significant differences in ORR (16 vs. $15.9 \%)$ or 
Table 1 Chemotherapy in P-NETs: results from phase III and selected phase II trials

\begin{tabular}{|c|c|c|c|c|c|c|}
\hline Author & Phase & $\begin{array}{l}\mathrm{N} \text { total } \\
(\mathrm{P}-\mathrm{NET} *)\end{array}$ & Treatment & ORR $(\%)$ & mPFS (months) & mOS (months) \\
\hline \multicolumn{7}{|c|}{ Classical regimens based on STZ, DOXO and DTIC } \\
\hline $\begin{array}{l}\text { Moertel et al } \\
1980[11]\end{array}$ & III & 84 & $\mathrm{STZ}+5-\mathrm{FU}$ vs STZ & 63.0 vs 36.0 & NR & $\begin{array}{l}26.0 \text { vs } 16.5 \\
(\mathrm{P}=\mathrm{ns})\end{array}$ \\
\hline $\begin{array}{l}\text { Moertel et al } \\
1992[12]\end{array}$ & III & 105 & $\begin{array}{l}\text { STZ + DOXO vs } \\
\text { STZ + 5-FU vs CTZ }\end{array}$ & $\begin{array}{l}69.0 \text { vs } 45.0 \text { vs } 30.0 \\
(P=0.005)\end{array}$ & $\begin{array}{l}20.0 \text { vs } 6.9 \text { vs NR }{ }^{b} \\
(P<0.001)\end{array}$ & $\begin{array}{l}26.4 \text { vs } 16.8 \text { vs } 18 \\
(\mathrm{P}<0.004)\end{array}$ \\
\hline $\begin{array}{l}\text { Meyer et al } \\
2014[13]\end{array}$ & II & $86(41)$ & $\begin{array}{l}\mathrm{STZ}+\mathrm{CAP} \text { vs } \\
\mathrm{STZ}+\mathrm{CAP}+\mathrm{CDDP}\end{array}$ & 12 vs. $16^{\mathrm{a}}$ & $\begin{array}{l}10.2 \text { vs } 9.7^{\mathrm{a}} \\
(\mathrm{HR} 0.74 / \mathrm{P}=\mathrm{NR})\end{array}$ & $\begin{array}{l}26.7 \text { vs } 27.5^{\mathrm{a}} \\
(\mathrm{HR} 1.16 / \mathrm{P}=\mathrm{NR})\end{array}$ \\
\hline Ramanathan RK et al. 2001[15] & II & 52 & DTIC (high dose) & 34.0 & NR & 19.3 \\
\hline $\begin{array}{l}\text { Bajetta E. et al } \\
1998[17]\end{array}$ & II & $30(15)$ & $\mathrm{DTIC}+5-\mathrm{FU}+\mathrm{EPI}$ & 27.0 & NR & Not reached \\
\hline Bajetta E et al. 2002 [16] & II & $82(28)$ & $\mathrm{DTIC}+5-\mathrm{FU}+\mathrm{EPI}$ & $24.4^{\mathrm{a}}$ & $21.0^{\mathrm{a} / \mathrm{b}}$ & $38.0^{\mathrm{a}}$ \\
\hline $\begin{array}{l}\text { Ducreux et al } \\
2014[14]\end{array}$ & II & 34 & $\mathrm{BEVA}+5-\mathrm{FU}+\mathrm{STZ}$ & 52.0 & 26.3 & Not reached \\
\hline \multicolumn{7}{|c|}{ Temozolomide and Capecitabine based regimens } \\
\hline $\begin{array}{l}\text { Pamela L. Kunz et al. } 2018 \\
\text { [31] }\end{array}$ & II & 144 & CAPTEM vs TEM & 33.3 vs 27.8 & $\begin{array}{l}22.7 \text { vs } 14.4 \\
(\text { HR } 0.58 / \mathrm{P}=0.023)\end{array}$ & $\begin{array}{l}\text { Not reached vs } 38.0 \\
(\mathrm{HR} 0.41 / \mathrm{P}=0.012)\end{array}$ \\
\hline Pavlakis N et al. 2020 [36] & II & 28 & $\begin{array}{l}\text { CAPTEM vs } 177 \mathrm{Lu}-\text { Octreo- } \\
\text { tate + CAPTEM }\end{array}$ & 33.3 vs 66.7 & NR & NR \\
\hline $\begin{array}{l}\text { Claringbold P.G et al. } 2016 \\
\text { [35] }\end{array}$ & II & 30 & CAPTEM + 177Lu-Octreotate & 80.0 & 48.0 & Not reached \\
\hline $\begin{array}{l}\text { Fine et al } \\
2014[50]\end{array}$ & II & $28(11)$ & CAPTEM & 36.0 & Not reached & Not reached \\
\hline $\begin{array}{l}\text { Kulke et al } \\
2006[20]\end{array}$ & II & $29(11)$ & TEM + Thalidomide & 45.0 & Not reached & Not reached \\
\hline $\begin{array}{l}\text { Chan JA et al } \\
2012[21]\end{array}$ & II & $34(15)$ & TEM + BEVA & 33.0 & 14.3 & 41.7 \\
\hline $\begin{array}{l}\text { Chan JA et al } \\
2013 \text { [22] }\end{array}$ & $\mathrm{I} / \mathrm{II}$ & 40 & $\mathrm{TEM}+\mathrm{EVE}$ & 40.0 & 15.4 & Not reached \\
\hline \multicolumn{7}{|c|}{ Platinum, 5-FU or other cytotoxic-based regimens } \\
\hline $\begin{array}{l}\text { Moertel et al } \\
1991[41]\end{array}$ & II & $45(14)$ & $\mathrm{CDDP}+\mathrm{VP}-16$ & 14.0 & 4.0 & 15.5 \\
\hline Fjällskog ML et al. 2001 [42] & II & $36(11)$ & $\mathrm{CDDP}+\mathrm{VP}-16$ & 27.0 & NR & $\begin{array}{r}13.0 \text { (including } 11 \\
\text { NETs + } 4 \text { NECs) }\end{array}$ \\
\hline $\begin{array}{l}\text { Bajetta et al } \\
2007[43]\end{array}$ & II & $27(11)$ & XELOX & 27.3 & $20.0^{\mathrm{a} / \mathrm{b}}$ & $40.0^{\mathrm{a}}$ \\
\hline $\begin{array}{l}\text { Kunz PL et al } \\
2016 \text { [44] }\end{array}$ & II & 16 & XELOX + BEVA & 18.8 & 15.7 & 38.0 \\
\hline $\begin{array}{l}\text { Kunz PL et al } \\
2016 \text { [44] }\end{array}$ & II & 12 & FOLFOX + BEVA & 50.0 & 21.0 & 31.0 \\
\hline $\begin{array}{l}\text { Berruti et al } \\
2014[51]\end{array}$ & II & $45(19)$ & $\mathrm{CAP}+\mathrm{BEVA}+\mathrm{OCT}$ & 26.3 & 14.3 & Not reached \\
\hline $\begin{array}{l}\text { Ducreux et al } \\
2006[39]\end{array}$ & II & $20(10)$ & FOLFIRI & 10.0 & $5.0^{\mathrm{a}}$ & $15.0^{\mathrm{a}}$ \\
\hline $\begin{array}{l}\text { Brixi-Benmansour et al. } \\
2011[38]\end{array}$ & II & 20 & FOLFIRI & 5.0 & 9.1 & NR \\
\hline $\begin{array}{l}\text { Grande et al } \\
2019 \text { [45] }\end{array}$ & II & 17 & SUN + EVO & 17.6 & 10.38 & Not reached \\
\hline
\end{tabular}

BEVA Bevacizumab, CAP capecitabine, CAPTEM capecitabine-temozolomide, CDDP cisplatin, CTZ chlorozotocin, DOXO doxorubicin, DTIC dacarbazine, EPI epirubicin, EVE everolimus, EVO Evofosfamide, FOLFIRI 5-fluorouracile- Irinotecan, FOLFOX 5-fluorouracile-oxaliplatin, $m$ months, $m O S$ median overall survival, $m P F S$ median progression free survival, NETs neuroendocrine tumors, NECs neuroendocrine carcinomas, $N R$ not reported, $n s$ non signicant, $O C T$ octreotide, ORR objective response rate, $P$-NETs pancreatic neuroendocrine tumors, $S T Z$ streptozocin, $S U N, T E M$ temozolomide; $V P$-16 etoposide, $y$ years, XELOX capecitabine-oxaliplatin

*If more histologies included

${ }^{a}$ In the entire cohort, not specific of P-NETs

${ }^{\mathrm{b}}$ TTP time to tumor progression 
PFS (5.3 vs. 4.5 months) among study arms, but survival was significantly greater for patients treated with STZ-5FU (24.3 vs. 15.7 months, $\mathrm{P}=0.027$ ). Hematologic toxicities were the major treatment-related toxicities for both DOXO5FU and STZ-5FU, and mild to moderate renal toxicity was reported in 40 (34.8\%) of STZ-5FU-treated patients. The RR of crossover DTIC treatment was $8.2 \%$, with a median survival of 11.9 months. The authors conclude that STZ$5 \mathrm{FU}$ is the treatment of choice when chemotherapy is judged to be an option for selected patients with carcinoid tumors. Thereafter, a small randomized trial that included 64 patients with advanced carcinoids (including 6 P-NETs and 58 EPNETs) compared STZ-5FU with INF $\alpha-2 A$. Despite a trend in favor of IFN, there was no significant differences in PFS and OS among study arms, and there was only one partial response documented in the chemotherapy arm [55]. DTIC was also assessed at high and low doses in 56 patients with advanced carcinoids (28 small bowel, 7 lung, 14 unknown primary and 7 other) with an overall RR of $16 \%$ (20\% at high doses) and a median survival of 20 months [56]. A retrospective study by Turner et al. evaluated the efficacy of STZ5-FU in combination with CDDP in 79 patients, 33 with EP-NENs. A RR of $25 \%$ was reported for non-pancreatic primary sites (vs 38\% for P-NENs), but these included both NETs and NECs and RRs by subgroup were not specified [57]. Moreover, the addition of CDDP to STZ-CAP did not demonstrate greater efficacy compared to STZ-CAP in a randomized study that included 86 patients with advanced NETs of pancreatic $(\mathrm{N}=41)$, gastroduodenal $(\mathrm{N}=17)$ or unknown primary $(\mathrm{N}=18)$, while the 3 -drug regimen was significantly more toxic [13].

More recently, following success of these agents in the treatment of P-NETs, capecitabine and temozolomide have been explored in EP-NETs with less encouraging results. CAP in monotherapy showed no ORR in the first trial conducted by Medley et al. in EP-NETs [58], but its combination with bevacizumab or bevacizumab and octreotide in the BETTER and XELBEVOC prospective trials, demonstrated an ORR of 12-18\% [51, 59]. Despite retrospective studies showed interesting data of TEM in limited numbers of lung NETs $(\mathrm{N}=13,31 \%$ achieved a partial response) [60], prospective studies have not confirmed these results. Clinical trials evaluating TEM combinations generally included a small number of EP-NETs (carcinoids) and their results were quite discouraging, with ORR of $7 \%$ with TEM-thalidomide [20] and 0\% with TEM-bevacizumab combinations [21]. More recently, preliminary results of the ATLANT study that assessed the combination of TEM and lanreotide in 40 lung or thymus NETs reported only 1 partial response (2.5\%) and a median PFS of 9.2 months [61].

Regarding the CAPTEM combination evidence in EPNETs is rather poor. One of the largest retrospective series to date included 65 NET patients treated with CAPTEM;
19 of them (28\%) were of non-pancreatic origin (9 lung, 7 GI and 3 unknown primary). ORR seemed lower in EPNETs (37\%) than in P-NETs (48\%). Median PFS and OS was 16.1 months and 38.3 months, respectively, with no significant differences between P- and EP-NETs [30]. Two small retrospective series that included 20-33 patients with lung NETs treated with CAPTEM reported an ORR of $18-30 \%$, a median PFS of $9-13$ months and a median OS of 30-68 months [62]. A phase II trial evaluated this combination in a heterogeneous patient population with NETs. Preliminary results of the first 28 patients recruited (11 P-NETs, 12 non-pancreatic carcinoids, 2 medullary thyroid carcinomas and 3 pituitary adenomas) were presented at ASCO GI in 2014, but the study has not been published to date. An ORR of 33\% was reported for carcinoids (30\% for typical and $50 \%$ for atypical), although their primary tumor site was not specified. A very similar rate was reported for P-NETs (36\%) [50]. Therefore, CAPTEM may be considered for patients with highly proliferative, rapidly progressive nonpancreatic NETs and/or those refractory to or not suitable for other treatment options, although available evidence to support its use is weak.

CAPTEM has also been explored in combination with ${ }^{177}$-Lu-Octreotate in a phase I/II trial that accrued 35 patients with advanced NETs. The overall ORR was 53\% [34], including $15 \%$ complete responses. Response rates were higher in patients with gastropancreatic NETs $(82 \%)$ than in those with bowel primaries (26\%), while the 2 lung NET patients included only achieved disease stabilization. Based on these results, the AGITG CONTROL NET Study midgut cohort $(\mathrm{N}=45)$ randomized $(2: 1)$ patients to receive PRRT and CAPTEM vs PRRT alone. Preliminary results showed numerically higher ORR for the combination (31 vs. $15 \%$ ) with no clear PFS benefit (PFS rate at 15 months: 92 vs. $90 \%$ ), and at the expense of greater mielotoxicity. Longer follow-up is needed to assess whether the increased RR is translated or not to a clinically meaningful PFS benefit to justify the increased toxicity associated with the combination [36].

Finally, platinum-based regimens have been particularly assessed in lung NETs given their efficacy in small cell lung NECs. Several small retrospective studies evaluated platinum-etoposide in typical and atypical lung carcinoids and documented ORRs of 23 to $39 \%$; one of them reported a median PFS of 7 months [42, 63-65]. One of these studies, that included 36 patients (15 P-NETs and 21 EP-NETs), reported a superior efficacy of platinum-etoposide in lung or thymus NETs (RR 39\%) than in NETs of pancreatic origin $(27 \%)$ [42]. Among patients with lung NETs treated with XELOX in the prospective trial by Bajetta et al. [43], ORR $(60 \%)$ seemed superior to that observed in P-NETs, although numbers of patients per subgroup are so small that no firm conclusions may be drawn in this regard. Table 2 
Table 2 Chemotherapy in EP-NETs: results from phase III and selected phase II trials

\begin{tabular}{|c|c|c|c|c|c|c|}
\hline Author & Phase & $\mathrm{N}(\mathrm{GI} / \mathrm{L})$ & Treatment & ORR $(\%)$ & mPFS (months) & mOS (months) \\
\hline \multicolumn{7}{|c|}{ Classical regimens based on STZ, DOXO and DTIC } \\
\hline $\begin{array}{l}\text { Moertel et al } \\
1979[52]\end{array}$ & III & $118(50 / 17)$ & $\mathrm{STZ}+5-\mathrm{FU}$ vs STZ + CTX & $\begin{array}{l}33.0 \text { vs } 26.0 \text { (GI: } 36.4 \\
\text { vs. } 37.5 / \mathrm{L}: 28.6 \text { vs } \\
0.0)\end{array}$ & NR & 11.2 vs 12.5 \\
\hline Engstrom et al.1984 [53] & II/III & $172(85 / 18)$ & 5-FU + STZ vs DOXO & 22.0 vs 21.0 & NR & $\begin{array}{l}16.0 \text { vs } 12.0 \\
(\mathrm{P}=\mathrm{ns})\end{array}$ \\
\hline $\begin{array}{l}\text { Sun et al } \\
2005[54]\end{array}$ & II/III & $176(55 / 22)$ & $\begin{array}{c}\mathrm{DOXO}+5 \mathrm{FU} \text { vs } \\
\mathrm{STZ}+5-\mathrm{FU}\end{array}$ & $\begin{array}{l}15.9 \text { vs } 16.0 \\
(\mathrm{P}=\mathrm{ns})\end{array}$ & $\begin{array}{l}4.5 \text { vs } 5.3 \\
(\mathrm{P}=\mathrm{ns})\end{array}$ & $\begin{array}{l}15.7 \text { vs } 24.3 \\
(P=0.027)\end{array}$ \\
\hline $\begin{array}{l}\text { Sun et al } \\
2005[54]\end{array}$ & II/III & $61(21 / 11)$ & DTIC & 8.2 & $\mathrm{NR}$ & 11.9 \\
\hline $\begin{array}{l}\text { Dahan et al } \\
2009[55]\end{array}$ & III & $64(42 / 3)$ & $\mathrm{INF} \alpha-2 \mathrm{~A}$ vs $\mathrm{STZ}+5 \mathrm{FU}$ & 9.0 vs 3.0 & $\begin{array}{l}14.1 \text { vs } 7.3 \\
(\mathrm{HR} 0.75 / \mathrm{P}=0.25)\end{array}$ & $\begin{array}{l}44.3 \text { vs } 30.4 \\
(P=0.83)\end{array}$ \\
\hline $\begin{array}{l}\text { Bokowski et al } \\
1994 \text { [56] }\end{array}$ & II & $56(28 / 7)$ & DTIC & 15.0 & $\mathrm{NR}$ & 20.0 \\
\hline $\begin{array}{l}\text { Bajetta E. et al } \\
1998[17]\end{array}$ & II & $30(6 / 3)$ & $\mathrm{DTIC}+5-\mathrm{FU}+\mathrm{EPI}$ & 30.0 (GI:17.0/L: NR) & Not reached & Not reached \\
\hline Bajetta E et al. 2002 [16] & II & $82(17 / 7)$ & $\mathrm{DTIC}+5-\mathrm{FU}+\mathrm{EPI}$ & 24.4 (L:14.0) & $21.0^{\mathrm{b}}$ & 38.0 \\
\hline $\begin{array}{l}\text { Meyer et al } \\
2014[13]\end{array}$ & II & $86(17 / 0)$ & $\begin{array}{l}\mathrm{STZ}+\mathrm{CAP} \text { vs } \\
\mathrm{STZ}+\mathrm{CAP}+\mathrm{CDDP}\end{array}$ & 12.0 vs 16.0 & $\begin{array}{l}10.2 \text { vs } 9.7 \\
(P=N R / H R 0.74)\end{array}$ & $\begin{array}{l}26.7 \text { vs } 27.5 \\
(\mathrm{HR} 1.16 / \mathrm{P}=\mathrm{NR})\end{array}$ \\
\hline \multicolumn{7}{|c|}{ Capecitabine and Temozolomide based combinations } \\
\hline Ferolla et al. 2020 [61] & II & $40(0 / 36)$ & $\mathrm{LAN}+\mathrm{TEM}$ & 2.5 & 9.2 & Not reached \\
\hline $\begin{array}{l}\text { Kulke et al } \\
2006[20]\end{array}$ & II & $29\left(11^{\mathrm{a}}\right)$ & TEM + Thalidomide & $25\left(7.0^{\mathrm{a}}\right)$ & Not reached & Not reached \\
\hline $\begin{array}{l}\text { Chan JA et al } \\
2012[21]\end{array}$ & II & $34\left(19^{\mathrm{a}}\right)$ & TEM + BEVA & $15\left(0.0^{\mathrm{a}}\right)$ & $11.0\left(7.3^{\mathrm{a}}\right)$ & $33.3\left(18.8^{\mathrm{a}}\right)$ \\
\hline $\begin{array}{l}\text { Mitry et al } \\
2014 \text { [59] }\end{array}$ & II & $49(49 / 0)$ & $\mathrm{CAP}+\mathrm{BEVA}$ & 18.0 & 23.4 & Not reached \\
\hline $\begin{array}{l}\text { Claringbold P.G et al. } 2012 \\
\text { [34] }\end{array}$ & II & $35(15 / 2)$ & $\begin{array}{l}\text { CAPTEM + 177-Lu- } \\
\text { Octreotate }\end{array}$ & 53.0 & 31.0 & Not reached \\
\hline $\begin{array}{l}\text { Fine et al } \\
2014[50]\end{array}$ & II & $28(0 / 12)$ & CAPTEM & $\begin{array}{l}43.0 \\
(\mathrm{~L}: 41.0)\end{array}$ & Not reached & Not reached \\
\hline $\begin{array}{l}\text { Berruti et al } \\
2014[51]\end{array}$ & II & $26(13 / 8)$ & $\mathrm{CAP}+\mathrm{BEVA}+\mathrm{OCT}$ & 11.5 & $\begin{array}{l}14.9 \\
\text { (GI:14.3/L: 18.6) }\end{array}$ & $\begin{array}{l}\text { Not reached } \\
\text { (L: 38.0) }\end{array}$ \\
\hline Pavlakis et al. 2020 [36] & II & $47(47 / 0)$ & $\begin{array}{l}\text { CAPTEM + PRRT vs. } \\
\text { PRRT }\end{array}$ & 31.3 vs 15.4 & Not reached & Not reached \\
\hline \multicolumn{7}{|l|}{ Platinum-based regimens } \\
\hline Moertel et al. 1991 [41] & II & $27\left(13^{\mathrm{a}}\right)$ & $\mathrm{CDDP}+\mathrm{VP}-16$ & $7.0\left(0.0^{\mathrm{a}}\right)$ & $\operatorname{NR}\left(3.0^{\mathrm{a}}\right)$ & $15.0\left(10.5^{\mathrm{a}}\right)$ \\
\hline $\begin{array}{l}\text { Fjällskog ML et al. } 2001 \\
\text { [42] }\end{array}$ & II & $36(3 / 18)$ & $\mathrm{CDDP}+\mathrm{VP}-16$ & $\begin{array}{l}36.0 \\
(G I: 33.0 / L: 39.0)\end{array}$ & NR & $\begin{array}{l}19.0 \\
(G I: 10 / L: 26.0)\end{array}$ \\
\hline $\begin{array}{l}\text { Bajetta et al } \\
2007[43]\end{array}$ & II & $27(8 / 5)$ & XELOX & $\begin{array}{l}30,0 \\
\text { (GI:0.0/L: 60.0) }\end{array}$ & $20.0^{\mathrm{b}}$ & 40.0 \\
\hline $\begin{array}{l}\text { Kunz PL et al } \\
2016[44]\end{array}$ & II & 20 & XELOX + BEVA & 5.0 & 19.1 & 42.2 \\
\hline $\begin{array}{l}\text { Kunz PL et al } \\
2016[44]\end{array}$ & II & 22 & FOLFOX + BEVA & 18.0 & 19.3 & 33.1 \\
\hline
\end{tabular}

BEVA Bevacizumab, CAP capecitabine, CAPTEM capecitabine-temozolomide, $C D D P$ cisplatin, $C T X$ cyclophosphamide, DOXO doxorrubicin, $D T I C$ dacarbazine, EPI epirubicin, EVE everolimus, FOLFOX 5-fluorouracile-oxaliplatin, GI gastrointestinal, $L$ lung, $L A N$ lanreotide autogel, $m$ months, $m O S$ median overall survival, $m P F S$ median progression free survival, $N R$ not reported, $n s$ non signicant, $O C T$ octreotide, $O R R$ objective response rate, PRRT peptide receptor radionuclide therapy, STZ streptozocin, TEM temozolomide, VP-16 etoposide, XELOX capecitabineoxaliplatin, 5-FU 5-fluorouracil

${ }^{\text {a } E P-N E T s ~ o r ~ c a r c i n o i d s ~ n o t ~ o t h e r w i s e ~ s p e c i f y ~}$

${ }^{\mathrm{b}}$ TTP time to tumor progression 
summarizes the results of phase III and selected phase II chemotherapy trials in EP-NETS.

A systematic meta-analysis by Lamarca et al. of 20 studies (one randomized phase III trial, 2 randomized phase II studies, 10 single-arm phase II trials and 7 retrospective analyses) and 264 patients (median of 11 patients per study, range 6-49) suggests a limited role of chemotherapy in EPNETs and points out the poor quality evidence of chemotherapy studies in this context (evidence level-C due to small patient numbers and heterogeneous populations and treatments) [66]. The mean OR, PFS and OS were $11.5 \%$ (95\%-CI 5.8-17.2), 16.9 months (95\%-CI 3.8-30.04) and 32.2 months (95\%-CI 10.4-54.2), respectively. In the trials including both P-NETs and EP-NETs the ORR was lower in EP- than in P-NETs [odds ratio (OR) 0.35 (95\% CI 0.18-0.66)] but the significance of this difference was lost when the studies with higher risk of bias were excluded. Well-designed, site-specific prospective studies are greatly needed to properly assess the role of chemotherapy in this setting.

\section{Key Messages}

- Chemotherapy has limited efficacy in EP-NETs, and thus its use is not recommended on a routine basis.

- Chemotherapy may only be considered in selected individuals with rapidly progressive advanced EP-NETs upon failure of other more effective therapeutic options including somatostatin analogues, everolimus, PRRT and/or locoregional ablative therapies.

- STZ- or TEM-based regimens are the preferred treatment options when chemotherapy is judged to be indicated in selected patients with EP-NETs. Platinum-based combinations may also be considered, particularly in lung NETs.

- Quality of evidence regarding chemotherapy outcomes assessment in EP-NETs is poor and the performance of site-specific clinical trials are highly encouraged to reliably establish the role, if any, of chemotherapy in each particular setting.

\section{Role of chemotherapy in neuroendocrine carcinomas}

\subsection{First-line chemotherapy}

Evidence to support treatment recommendations for extrapulmonary G3 NECs is scarce and derives from limited retrospective series or tumor registries and very few small noncontrolled clinical trials $[67,68]$. Most clinicians, therefore, treat this entity in analogy to the much more common small cell lung NEC or small cell lung carcinoma (SCLC) due to their histological and clinical resemblance. Poorly differentiated extra-pulmonary NECs have also a very aggressive behavior with a median OS of up to 12 months with best available therapy, and of barely 1 month in patients who only receive supportive care [69]. Treatment with CDDP and etoposide (VP-16) has been the classical approach by analogy with SCLC [67]. The first non-randomized phase II study assessing the efficacy of this regimen in NECs was published in 1991 by Moertel et al. [41]. This study reported a RR of $67 \%$ (including $17 \%$ of complete responses) with a median OS of 19 months. Neuro- and nephro-toxicity were reported in $24 \%$ and $66 \%$ of patients, respectively. Bone marrow suppression, alopecia and gastrointestinal toxicity were also frequently encountered adverse events. Thereafter, several small retrospective studies have reported ORRs for this regimen that widely range from 17 to $63 \%$ [70-74]. More recent large tumor registries have confirmed the efficacy of CDDP-VP-16 in this setting, although ORRs (28-48\%) are generally lower than those reported for SCLC [69, 75-78].

Real world data from the NORDIC study [69], that reported results of 305 patients with G3 NECs from 12 Nordic European hospitals, showed very similar efficacy for the combination of carboplatin versus cisplatin with etoposide in this setting. This supports the use of the carboplatin combination given its overall improved tolerability as it is not associated with renal nor neurotoxicity. The most relevant negative prognostic factors for survival were colorectal primary tumor site, poor performance status (PS) and elevated platelets or lactate dehydrogenase (LDH) levels. This study also documented that NECs with Ki-67 $<55 \%$ had a lower response rate to platinum-based therapy ( $15 \%$ versus $42 \%, \mathrm{P}<0.001)$, although better survival than patients with Ki-67 $\geq 55 \%$ (14 versus 10 months, $\mathrm{P}<0.001$ ). Based on this observation alternative chemotherapy regimens are generally recommended for these patients. In the prospective French national registry published in 2017 [75], which included GEP NECs $(\mathrm{N}=202)$ and NECs of unknown origin $(\mathrm{N}=51)$, $69 \%$ of the patients received first line chemotherapy, $40 \%$ second line and $20 \%$ third line. In this study only PS and the number of metastatic sites were identified as independent prognostic features. The Ki-67 cut-off value of 55\% and primary site identified by Sorbye et al. were not confirmed as prognostic variables. In the French study PE was the treatment of choice in first line (86\%) and was associated with an ORR of $50 \%$ and a median OS of 11,6 months. There is no prospective data assessing the carboplatin and etoposide combination in NECs. In the largest retrospective study published in 2019 by Frizziero et al. [76] patients with extrapulmonary NECs were treated with carboplatin-etoposide as first line $(\mathrm{N}=106)$, second line $(\mathrm{N}=16)$ or third line $(\mathrm{N}=1)$ therapy for advanced disease. Carboplatin-etoposide achieved an ORR of $44,3 \%$ in the first line setting and of 
$23,5 \%$ as second- or third-line therapy. The PFS and OS for first and after-first line treatment were 6 and 11,5 months and 4,5 and 12,5 months, respectively. No differences in DCR were observed between intravenous or oral etoposide. As in the French registry, the Ki-67 cut-off value 55\% was not a predictive factor for response nor prognostic. Carboplatin and etoposide have been also evaluated in combination with paclitaxel in a phase II trial by Hainsworth et al. [79] that included 78 NECs. The ORR was 53\%, including 15\% complete responses, and was similar regardless of histology or primary tumor site. The median, 2-year, and 3-year survivals for these patients were 14.5 months, $33 \%$, and $24 \%$, respectively. Toxicity was however significant, with G3-4 neutropenia developed by $82 \%$ and hospitalization required in $19 \%$ of patients. Carboplatin-etoposide is also being currently explored in the NICE-NEC trial (NCT03980925) in combination with nivolumab in chemonaïve patients with G3 GEP NENs or NENs of unknown origin [80]. The results of this trial are expected for 2022.

Several retrospective studies, mostly from Asia, have assessed the efficacy of first line irinotecan and platinum (IP) in NECs with ORR ranging from 25 to $75 \%$ and OS of about 12 months [74, 81-85]. A phase II study of IP in high grade NENs that included 20 patients with extrapulmonary NECs reported an ORR of 58\% [86]. A randomized Asian study (NCT03168594) is currently comparing CCDP and irinotecan versus CDDP and VP-16 efficacy in GEP NECs [87]. TEM-based regimens have been barely assessed in chemonaïve patients with high grade NECs and are preferentially considered for high-grade NENs with Ki-67 index in the lower range (21-55\%) and/or in those with well differentiated tumors (G3 NETs), although evidence to support this recommendation is not too solid $[67,69]$. A phase II randomized trial (NCT02595424) is currently comparing CDDP and VP-16 versus CAPTEM in advanced G3 non-small cell GEP NECs and shall help clarify the relative efficacy of these regimens in this setting [88].

Fluoropyrimidine-based regimens with irinotecan or oxaliplatin are generally reserved for second line therapy although many experts advocate their use upfront in large cell NECs of the GI tract, particularly if they are associated with a non-neuroendocrine component (MINEN). A phase II trial has recently evaluated the combination of capecitabine, oxaliplatin and irinotecan (CAPOXIRI) with bevacizumab as first line therapy in 22 gastrointestinal NEC patients followed by pazopanib and capecitabine as maintenances therapy in responders or carboplatin and etoposide in non-responders [89]. Four-drug combination showed an ORR of $47,5 \%$ meeting the primary end-point of the study, although this figure does not substantially differ from historical ORR reported for the combination of platinum-etoposide. The toxicity profile was not negligible with G3-4 hematological and non-hematological encountered in 8 and 34 patients, respectively. Median PFS and OS was superior for responders to CAPOXIRI-BEVA than for non-responders: 18 and 30,5 months vs 5 and 14 months, respectively. These results suggest that the switch maintenance strategy in nonresponders does not seem to have a major impact on patients' outcomes, but it is difficult to interpret what is the added value of pazopanib maintenance in responders versus bevacizumab or fluoropyrimidines alone in this setting. Randomized studies are needed to address whether 3- or 4-drug regimens can significantly improve efficacy or just increase toxicity.

\subsection{Second or subsequent lines of therapy}

There is not an established second line treatment for NEC patients. Re-challenge with platinum-etoposide may be considered after a break of at least 3-6 months in patients that responded to first line treatment in the absence of significant residual toxicity (neurotoxicity, ototoxicity...). In the NORDIC study the median ORR for the 84 assessable patients that received second line chemotherapy (35 TEM-based and 20 taxotere-based regimens) was $18 \%$ and the median survival from start of first-line chemotherapy 19 months. FOLFIRI, FOLFOX or XELOX are currently the most commonly used regimens after platinum-etoposide failure [67]. Retrospective studies showed ORRs in the second-line setting of about $30 \%$ and PFS of 4-5 months [90-92]. Second line therapy in the French observational study reported ORR of $24 \%$ and $16 \%$ with FOLFIRI and FOLFOX, respectively, and a median OS $<6$ months [75]. Temozolomide has been also explored in NECs, although its efficacy seems to be lower than in NETs. Whereas a small retrospective study by Weling et al. reported an ORR of 33\% with TEM alone or in combination with capecitabine and bevacizumab in 25 NECs [93], no responses were observed with TEM alone in another cohort of 28 NECs [94]. In the phase II trial conducted with TEM in monotherapy in NECs by Kobayashi et al., an ORR of $15 \%$ was reported with a median PFS and OS of 1,8 and 7,8 months, respectively [95]. TEM is therefore not generally recommended as single agent for the treatment of NECs. A recent meta-analysis including 19 studies and a total of 582 patients with extra-pulmonary NECs showed limited efficacy of second-line chemotherapy in this malignancy. Global median ORR was $18 \%$ (range 0-50), and the median PFS and OS were 2,5 and 7,6 months, respectively [96]. Table 3 summarizes prospective and and selected retrospective studies in NECs.

Several ongoing trials are currently assessing different treatment regimens in the second line setting of high grade NENs. These include the SENECA study, a randomized phase II trial comparing CAPTEM versus FOLFIRI (NCT03387592) [97], the BEVANEC study (NCT02820857), a phase II randomized trial assessing FOLFIRI with or without bevacizumab upon progression to 
Table 3 Chemotherapy in NECs: Prospective and selected retrospective studies

\begin{tabular}{|c|c|c|c|c|c|c|c|}
\hline Author & Type of study & $\mathrm{N}$ & Primary site & Treatment & ORR $(\%)$ & mPFS (months) & mOS (months) \\
\hline \multicolumn{8}{|l|}{ First line } \\
\hline $\begin{array}{l}\text { Moertel et al. } 1991 \\
\text { [41] }\end{array}$ & II & 18 & $\begin{array}{l}\text { GEP }(14) / L \\
(1) / U(3)\end{array}$ & $\mathrm{CDDP}+\mathrm{VP}-16$ & 67.0 & 11.0 & 19.0 \\
\hline $\begin{array}{l}\text { Hainsworth } \\
\text { et al. } 2006 \text { [79] }\end{array}$ & II & 78 & $\begin{array}{l}\text { GEP }(15) / \mathrm{L}(7) / \mathrm{U} \\
(48) / \text { other }(8)\end{array}$ & Paclitaxel + CBDCA + VP-16 & 53.0 & 7.5 & 14.5 \\
\hline $\begin{array}{l}\text { Bajetta et al. } 2007 \\
\text { [43] }\end{array}$ & II & 13 & $\begin{array}{l}\text { GEP (5)/L (5)/ } \\
\text { other (3) }\end{array}$ & XELOX & 23.0 & $4.0^{\mathrm{b}}$ & 5.0 \\
\hline $\begin{array}{l}\text { Mani et al. } \\
2008[86]\end{array}$ & II & 20 & NEC (NR) & CDDP + IRI & 58.0 & $4.0^{\mathrm{b}}$ & NR \\
\hline $\begin{array}{l}\text { Alifieris et al. } 2020 \\
\text { [89] }\end{array}$ & II & 22 & GI & $\begin{array}{l}\text { CAPOXIRI-BEVA } \\
\text { PAZO + CAPE }\end{array}$ & 47.4 & 13.0 & 29.0 \\
\hline $\begin{array}{l}\text { Walter T et al. } \\
2017 \text { [75] }\end{array}$ & $\begin{array}{l}\text { NTR(RENATEN, } \\
\text { FFCD,TENpath) }\end{array}$ & 152 & GEP/U & $\begin{array}{l}\text { CDDP + VP-16 (113) } \\
\text { CBDCA + VP-16 (39) }\end{array}$ & 50.0 & 6.2 & 11.6 \\
\hline $\begin{array}{l}\text { Mitry et al. } 1999 \\
\text { [70] }\end{array}$ & Retrospective & 41 & $\begin{array}{l}\text { GEP (20)/L (10)/ } \\
\text { HN (4)/ U (7) }\end{array}$ & $\mathrm{CDDP}+\mathrm{VP}-16$ & 41.5 & 8.9 & 15.0 \\
\hline $\begin{array}{l}\text { Iwasa et al. } 2010 \\
\text { [71] }\end{array}$ & Retrospective & 21 & P (10)/ HB (11) & $\mathrm{CDDP}+\mathrm{VP}-16$ & 14.0 & 1.8 & 5.8 \\
\hline $\begin{array}{l}\text { Sorbye et al. } 2013 \\
\text { [69] }\end{array}$ & $\begin{array}{l}\text { NTR } \\
\text { (NORDIC) }\end{array}$ & 252 & GEP (174)/ U (78) & $\begin{array}{l}\text { CDDP + VP-16 (129) } \\
\text { CBDCA + VP-16 (67) } \\
\text { CBDCA + VP-16 + VINC(28) }\end{array}$ & $\begin{array}{l}31.0 \\
30.0 \\
44.0\end{array}$ & $\begin{array}{l}4.0 \\
4.0 \\
4.0\end{array}$ & $\begin{array}{l}12.0 \\
11.0 \\
10.0\end{array}$ \\
\hline $\begin{array}{l}\text { Yamaguchi, } 2014 \\
\text { [74] }\end{array}$ & Retrospective & 206 & GEP & $\begin{array}{l}\text { CDDP + VP-16 (46) } \\
\text { CDDP + IRI (160) }\end{array}$ & $\begin{array}{l}28.0 \\
50.0\end{array}$ & $\begin{array}{l}4.0 \\
5.2\end{array}$ & $\begin{array}{l}7.3 \\
13.0\end{array}$ \\
\hline $\begin{array}{l}\text { Frizziero } \\
\text { et al. } 2019 \text { [76] }\end{array}$ & Retrospective & 98 & $\begin{array}{l}\text { GEP (72)/ U (26)/ } \\
\text { other }^{\text {a }}\end{array}$ & CBDCA + VP-16 & 47.9 & 6.0 & 11.5 \\
\hline $\begin{array}{l}\text { Jimenez-Fonseca } \\
\text { et al. 2020 } \\
{[78,100]}\end{array}$ & NTR (RGETNE) & 279 & $\begin{array}{l}\text { GEP }(70 \%) \mathrm{U} \\
(16 \%)\end{array}$ & CDDP/CBDCA + VP-16 & 73.0 & 6.1 & 14 \\
\hline $\begin{array}{l}\text { Okita et al. } 2011 \\
\text { [82] }\end{array}$ & Retrospective & 12 & Gastric & CDDP + IRI & 75.0 & 7.0 & 22.6 \\
\hline $\begin{array}{l}\text { Nakano et al. } 2012 \\
\text { [84] }\end{array}$ & Retrospective & 28 & $\begin{array}{l}\text { GEP }(9) / \mathrm{U}(12) / \\
\text { others }(23)^{\mathrm{a}}\end{array}$ & CDDP + IRI & 64.0 & 7.3 & 16.0 \\
\hline $\begin{array}{l}\text { Ramella et al. } 2013 \\
\text { [81] }\end{array}$ & Retrospective & 28 & $\begin{array}{l}\text { GEP (19)/ U (6)/ } \\
\text { others (2) }\end{array}$ & $\begin{array}{l}\text { CDDP + IRI (25) } \\
\text { CBDCA + IRI (3) }\end{array}$ & 46.0 & $3.7^{\mathrm{b}}$ & 11.7 \\
\hline Lu et al. 2013 [85] & Retrospective & 16 & GEP & CDDP + IRI & 57.1 & 5.5 & 10.6 \\
\hline $\begin{array}{l}\text { Okuma et al. } 2014 \\
\text { [83] }\end{array}$ & Retrospective & 12 & Esophageal & CDDP + IRI & 50.0 & 4.0 & 12.6 \\
\hline \multicolumn{8}{|c|}{ Second line and beyond } \\
\hline $\begin{array}{l}\text { Kobayashi et al. } \\
2021 \text { [95] }\end{array}$ & II & 13 & $\begin{array}{l}\text { GEP }(10) / \mathrm{U}(1) / \\
\text { other }(2)\end{array}$ & TEM & 15.4 & 1.8 & 7.8 \\
\hline $\begin{array}{l}\text { Walter T et al. } \\
2017 \text { [75] }\end{array}$ & $\begin{array}{l}\text { NTR(RENATEN, } \\
\text { FFCD,TENpath) }\end{array}$ & 105 & GEP and U & $\begin{array}{l}\text { FOLFIRI (72) } \\
\text { FOLFOX (33) }\end{array}$ & $\begin{array}{l}24.0 \\
16.0\end{array}$ & $\begin{array}{l}2.9 \\
2.3\end{array}$ & $\begin{array}{l}5.9 \\
3.9\end{array}$ \\
\hline $\begin{array}{l}\text { Welin T et al. } 2011 \\
\text { [93] }\end{array}$ & Retrospective & 25 & $\begin{array}{l}\text { GEP (17)/ L (3)/ } \\
\text { U (5) }\end{array}$ & $\mathrm{TEM} \pm \mathrm{CAPE} \pm \mathrm{BVZ}$ & 33.0 & 6.0 & 22.0 \\
\hline $\begin{array}{l}\text { Olsen et al. } 2012 \\
\text { [94] }\end{array}$ & Retrospective & 28 & $\begin{array}{l}\text { GEP (18)/ L (1)/ } \\
\text { U (6) }\end{array}$ & TEM & 0.0 & 2.4 & 3.5 \\
\hline $\begin{array}{l}\text { Hentic et al. } 2012 \\
\text { [90] }\end{array}$ & Retrospective & 19 & GEP & FOLFIRI & 31.0 & 4.0 & 18.0 \\
\hline $\begin{array}{l}\text { Sorbye et al. } 2013 \\
\text { [69] }\end{array}$ & Retrospective & 100 & GEP and U & $\begin{array}{l}\text { Various }(35 \% \text { TEM, } 20 \% \\
\text { taxanos...) }\end{array}$ & 18.0 & NR & 19.0 \\
\hline $\begin{array}{l}\text { Ferrarotto et al. } \\
2013 \text { [91] }\end{array}$ & Retrospective & 24 & $\begin{array}{l}\text { GEP (18)/ L (4)/ } \\
\text { U (2) }\end{array}$ & XELOX & 29.0 & $9.8^{b}$ & Not reached \\
\hline $\begin{array}{l}\text { Hadoux et al. } 2015 \\
\text { [92] }\end{array}$ & Retrospective & 20 & $\begin{array}{l}\text { GEP }(12) / \mathrm{L}(4) / \mathrm{U} \\
(2) / \text { other }(2)\end{array}$ & FOLFOX & 29.0 & 4.5 & 9.9 \\
\hline
\end{tabular}


Table 3 (continued)

\begin{tabular}{|c|c|c|c|c|c|c|c|}
\hline Author & Type of study & $\mathrm{N}$ & Primary site & Treatment & ORR $(\%)$ & mPFS (months) & mOS (months) \\
\hline $\begin{array}{l}\text { Yamaguchi, } 2014 \\
\text { [74] }\end{array}$ & Retrospective & 116 & GEP/ HB & $\begin{array}{l}\text { Amrubicin } \\
\text { CCDP or CBDCA + VP-16 } \\
\text { IRI } \\
\text { S-1 } \\
\text { CDDP + IRI }\end{array}$ & $\begin{array}{l}4.0 \\
17.0 \\
5.0 \\
27.0 \\
40.0\end{array}$ & $\begin{array}{l}1.9 \\
1.9 \\
2.2 \\
2.4 \\
4.8\end{array}$ & $\begin{array}{l}8.0 \\
5.0 \\
6.0 \\
12.0 \\
9.0\end{array}$ \\
\hline $\begin{array}{l}\text { Frizziero et al. } \\
2019 \text { [76] }\end{array}$ & Retrospective & 17 & GEP/ U/ other ${ }^{a}$ & $\mathrm{CBDCA}+\mathrm{VP}-16$ & 23.5 & 4.5 & 12.5 \\
\hline
\end{tabular}

BEVA Bevacizumab, CAPE capecitabine, CAPOXIRI Capecitabine, Oxaliplatin Irinotecan, CBDCA carboplatin, CDDP cisplatin, FFCD Fédération Francophonede Cancérologie Digestive, FOLFIRI 5-Fluorouracile-irinotecan, FOLFOX 5- Fluorouracile-oxaliplatin, GI gastrointestinal, GEP gastroenteropancreatic, $H B$ hepatobiliary, $H N$ head and neck, IP Irinotecan-platinum, IRI Irinotecan, $L$ lung, $M A N E C$ Mixed adenoneuroendocrine carcinoma, $m O S$ median overall survival, $m P F S$ median progression free survival, NEC neuroendocrine carcinoma, $N R$ not reported, NTR national tumor registry, $O R R$ overall response rate, $O S$ overall survival, PAZO Pazopanib, PFS progression free survival, RENATEN Groupe d'étude des Tumeurs Endocrines [GTE], RGETNE Registro del grupo español de tumores neuroendocrinos, TENpath Réseau national d'expertise pour le diagnostic anatomopathologique des tumeurs neuroendocrines de l'adulte, familiales et sporadiques, TTP time to tumor progression, $U$ unknown, VINC vincristine, VP-16 etoposide, XELOX capecitabine + Oxaliplatin

${ }^{a}$ Data from the entire cohort, no specific of the subgroup

${ }^{\mathrm{b}}$ TTP time to tumor progression

PE [98], and the NET-02 study (NCT03837977), a phase II randomized trial evaluating liposomal irinotecan (Nal-Iri) and 5-FU versus docetaxel as second line therapy in extrapulmonary NECs [99].

Key messages

- Poorly-differentiated neuroendocrine carcinomas have a very poor prognosis with a median OS of less than 12 months with best available therapy.

- Chemotherapy is an essential part of the multimodality approach for localized NECs and the mainstay of care in advanced disease, although no randomized trials have ever been conducted in G3 extra-pulmonary NENs.

- Platinum-etoposide combinations are the regimens of choice based on retrospective series or tumor registries and a few small non-controlled clinical trials, although RR reported in extra-pulmonary NECs are lower $(<50 \%)$ than those reported for SCLC. Carboplatin combinations are preferred over cisplatin ones as they seem to have similar efficacy, while the tolerance is better.

- Second line chemotherapy is not routinely recommended in NECs. Fluoropyrimidine-based chemotherapy, such as FOLFOX, FOLFIRI or CAPTEM, may be considered in subsequent lines of therapy in patients with good PS after careful discussion of potential risks and benefits with the patient.

- TEM- or STZ-based regimens are generally preferred for well-differentiated high grade neuroendocrine tumors (G3 NETs). Nevertheless, evidence to support this recommendation is scarce and efficacy of these regimens in this subset of patients shall be prospectively assessed.

\section{Treatment algorithm: when is chemotherapy indicated?}

\subsection{Indication of chemotherapy in NETs}

\author{
Adjuvant treatment \\ Adjuvant treatment is not recommended in G1-2 GEP- \\ NETs as recurrence rates are generally low and there are \\ no data to support postoperative therapy is of any value in \\ this context [68, 101, 102, 110]. Large retrospective stud- \\ ies have reported no benefit of adjuvant therapy in neither \\ typical nor atypical lung carcinoids [105-110]. \\ Therefore, adjuvant therapy is not routinely recommended \\ for lung NETs [101-104]. However, adjuvant chemotherapy \\ (platinum-based or temozolomide-based regimens), with \\ or without radiotherapy, may be considered in selected \\ fit patients with particularly high risk of relapse (i.e. N2 \\ atypical carcinoids with high proliferation index) after \\ multidisciplinary discussion $[102,105,106]$. \\ For thymic carcinoids, evidence is even poorer [111- \\ 114]. \\ Case-by-case discussion is recommended to decide addi- \\ tional local and/or systemic treatment options in thymic \\ carcinoids following R0 (if stage 3 or 4 ) or R1 or R2 \\ resection [104]. \\ Metastatic disease \\ Systemic chemotherapy is primarily indicated in \\ advanced progressive G1-2 NETs of pancreatic origin. \\ Chemotherapy may be considered upfront in P-NETs \\ with bulky disease also in the absence of documented
}


prior disease progression, particularly in tumors with Ki-67 index above 10\% [68, 101, 110, 111]. STZ-based chemotherapy has been the standard of care in P-NETs for many years, although the CAPTEM combination is being increasingly used since results from the ECOG-2211 trial suggest similar activity to the older regimen, and it is associated with improved tolerability and patients' convenience as it is orally administered. Both regimens are valid treatment options for P-NETs when chemotherapy is indicated, and are currently being compared head-tohead in the BETTER-2 trial. The optimal integration of chemotherapy with other treatment options in this setting is a matter of debate, and some ongoing trials (i.e. SEQTOR, COMPETE,..) shall provide relevant information in the near future to help clinicians optimize the sequential use of available treatment options in P-NETs. Regarding EP-NETs, efficacy of cytotoxic chemotherapy is rather limited and thus its use cannot be recommended on a routine basis. Chemotherapy may only be considered in selected individuals with rapidly progressive tumors upon failure of other more effective therapeutic options including somatostatin analogues, everolimus and/or PRRT $[68,102,115,116]$. There is no solid data to support any particular cytotoxic regimen in this setting, although the most commonly used are STZ-based, TEM-based or platinum-based regimens. Therefore, enrollment of patients in clinical trials is highly encouraged in this context whenever available.

\subsection{Indication of chemotherapy in NECs}

\section{Adjuvant treatment}

Chemotherapy is an essential part of the multimodality approach for localized NECs and the mainstay of care in advanced disease, although no randomized trials have ever been conducted in G3 extra-pulmonary NENs. Based on the high risk of systemic relapse after primary tumor resection, all experts and guidelines agree to recommend adjuvant systemic platinum-based chemotherapy following surgery in patients with localized NECs [67, 68, 101, 104, 116]. Cisplatin or carboplatin and etoposide for 4 to 6 cycles are generally recommended. Chemotherapy is also indicated in combination with radiotherapy for localized disease when surgery is not feasible or too morbid (i.e. esophageal primary).

\section{Metastatic disease}

Systemic chemotherapy is indicated in patients with advanced unresectable disease and adequate performance status and organ function. Otherwise, patients may be just offered best supportive care. The combinations of cisplatin or carboplatin with etoposide are the most widely used in NECs [67, 68, 101, 104, 116]. Carboplatin is generally preferred over cisplatin as it has similar anti- tumor activity and better toxicity profile [69]. Alternative regimenssubstituting irinotecan for etoposide are also acceptable first line options, more commonly used in Asia [74]. Although second-line regimens have not been evaluated rigorously either, the most widely accepted options include temozolomide-, irinotecan- or oxaliplatin-based schedules.

The optimal chemotherapy regimen for the recently recognized NET G3 entity is a matter of debate and has not been widely studied yet. G3 NETs generally have a Ki-67 in the lower G3 range (21-50\%) and a molecular profile that resembles that encountered in low grade NETs (mutations in DAXX/ATRX, MEN1 or mTOR pathway genes). They have better prognosis than G3 NECs although tumor response rates to platinum agents have been reported to be lower [69]. For these reasons most experts recommend to treat them as high-G2 NETs. Chemotherapy is the first choice of therapy in these patients but TEM- or STZ-based regimens are generally preferred. Nevertheless, prospective assessment of the efficacy of these regimens in this subset of patients is required and currently ongoing.

\section{Future perspectives}

Systemic therapies for NENs have considerably expanded over the past years, although options are still rather limited. Chemotherapy remains an essential component of the treatment strategy of patients with NENs, particularly for those with bulky, symptomatic or rapidly progressive tumors (generally G3 or high-G2 NENs). In the context of NETs, chemotherapy has a well-established role in the management of those of pancreatic origin, whereas its use in L- or GI-NETs is still debated. More recently developed targeted agents (sunitinib, surufatinib, everolimus) have unquestionable advantages, as they have been more adequately assessed versus best supportive care in large, well designed doubleblind placebo-controlled randomized trials, and they are orally available thereby improving patient's convenience. However, as opposed to chemotherapy, these novel targeted agents rarely induce tumor shrinkage, which is a relevant treatment goal in certain subgroups of patients, such as those with bulky, symptomatic disease or borderline-resectable locally advanced tumors. Nevertheless, randomized studies comparing the efficacy and safety of chemotherapy versus other treatment options such as targeted agents, locoregional ablative therapies or PRRT are certainly needed to properly position chemotherapy within the treatment algorithm of NENs. Further research is also needed to explore its efficacy when combined with other agents (mTOR inhibitors, tyrosine-kinase inhibitors, PRRT...) that act through different pathways, particularly those with no overlapping toxicities. 
But the major challenge ahead is to identify reliable predictive biomarkers that can help to more adequately select patients most likely to benefit from specific therapies, allowing to move from a "one-size-fits-all" towards a more personalized medicine. Traditional chemotherapeutic agents are cytotoxic by means of interfering with cell division (mitosis) or inducing DNA damage. Therefore, they are particularly toxic to rapidly dividing cells or cells with defects in DNA repair mechanisms. Consistent with this, a higher Ki-67 index or mitotic rate have been associated with increased response to cytotoxic agents, although robust data is lacking [117]. Moreover, both $\mathrm{Rb}$ loss and KRAS mutations have been described as predictors of response to platinum-based chemotherapy in G3 P-NENs. [118]. Other molecular alterations associated with platinum-sensitivity in other tumor types include p53 or BRCA mutations; the latter also confer sensitivity to PARP inhibitors [119], although this has not been explored in NENs to date. MGMT (O6-methylguanine DNA methyltransferase) methylation has demonstrated to predict efficacy of alkylating agents in glioblastoma multiforme [120]. MGMT deficiency has been globally related with a trend to a better RR, PFS and OS in NETs treated with alkylating agents (TEM, DTIC) in retrospective studies. Indeed, depletion of MGMT induced by capecitabine has been suggested as the rational for the CAPTEM synergy observed in NETs. Nevertheless, results are inconsistent among different studies maybe due to their heterogeneity (multiple sites of origin, different techniques to asses MGMT status, etc.) and need to be confirmed in prospective trials. [121].

Regarding NECs the results of several ongoing trials will provide very valuable quality data of the efficacy of different chemotherapy regimens in poorly differentiated NECs, both in chemonaïve and refractory carcinomas, and also in high grade well differentiated tumors (G3 NETs) [118]. Combination strategies with immunotherapy and PRRT are also being explored to potentially improve the poor outcomes of chemotherapy in NECs. It should also be noted that at present large and small cell NECs are generally treated in a similar way, although growing evidence suggests these entities differ from a molecular perspective, and this may translate into relevant differences in treatment outcome and prognosis. Small cell morphology is predominant in lung NECs whereas large cell is more commonly encountered in digestive NECs except for esophageal and anal canal primaries. Small cell NECs (SC-NECs) are molecularly more homogeneous and often characterized by bi-allelic inactivation of TP53 and RB1. Large cell NECs (LC-NECs) have a better prognosis than SC-NECs, and within LC-NECs, those of GI origin have a better prognosis than lung LC-NECs [122]. LC-NECs are molecularly more complex and heterogeneous, and up to $40 \%$ have a non-neuroendocrine component. At least 2 distinct molecular subtypes have been described in LC-NECs, a "small cell-like signature" (with a lower proportion of TP53 and RB1 mutations observed in extrapulmonary NECs than in lung NECs) and a "carcinoma-like signature" that resembles the molecular profile of the non-neuroendocrine tumors of similar anatomic site (i.e. KRAS mutations in pancreatic NECs, KRAS/BRAF/APC/TP53/MYC mutations in colorectal NECs) [123]. Despite these notable differences, however, clinical guidelines do not recommend to treat NECs differently according to the morphological or molecular subtype, basically due to the lack of data in this regard. Improved international collaboration is therefore urgently needed from the bench to the bedside in order to improve the clinical management and outcome of these patients. Large, well designed prospective clinical trials shall be encouraged to generate good quality data that is particularly needed in this clinical setting. Moreover, personalized treatment options shall be further explored in certain molecular subgroups, such as NECs harboring BRAF mutations, ALK, ROS1 or NTRK traslocations, high TMB or MSI [124-126]. Indeed, there are several drugs currently approved for molecularly-defined, tumor-agnostic indications, such as the immune check-point inhibitor pembrolizumab for the treatment of high TMB or MSI tumors, or the NTRK inhibitors larotrectinib or entrectinib for tumors harboring NTRK, ALK or ROS1 traslocations [127-130]. A deeper understanding of the molecular basis of NEN genesis and progression will be key to improve treatment efficacy and prognosis of these patients.

Acknowledgments ALS is funded by Instituto de Salud Carlos III (Contrato Rio Hortega). MCR is funded by AECC (CLSEN19003RIES).

Funding No funding was received to assist with the preparation of this manuscript. PEO has received honoraria or funding for continuous medical education from Ipsen, Novartis, Roche. MCRM Has provided scientific advice and/or received honoraria or funding for continuous medical education from Servier, Roche, Merck, AAA, Servier, Amgen and Bayer. RGC has provided scientific advice and/or received honoraria or funding for continuous medical education from AAA, Advanz Pharma, Amgen, Bayer, BMS, HMP, Ipsen, Merck, Midatech Pharma, MSD, Novartis, PharmaMar, Pfizer, Pierre Fabre, Roche, Servier and Sanofi, and has received research support from Pfizer, BMS and MSD.

\section{Declarations}

Conflict Of Interest ALS and BAP has no conflict of interests to declare.

Open Access This article is licensed under a Creative Commons Attribution 4.0 International License, which permits use, sharing, adaptation, distribution and reproduction in any medium or format, as long as you give appropriate credit to the original author(s) and the source, provide a link to the Creative Commons licence, and indicate if changes were made. The images or other third party material in this article are included in the article's Creative Commons licence, unless indicated otherwise in a credit line to the material. If material is not included in the article's Creative Commons licence and your intended use is not 
permitted by statutory regulation or exceeds the permitted use, you will need to obtain permission directly from the copyright holder. To view a copy of this licence, visit http://creativecommons.org/licenses/by/4.0/.

\section{References}

1. Dasari A, Shen C, Halperin D, Zhao B, Zhou S, Xu Y, et al. Trends in the Incidence, Prevalence, and Survival Outcomes in Patients With Neuroendocrine Tumors in the United States. JAMA Oncol. 2017;3(10):1335-42.

2. Nagtegaal ID, Odze RD, Klimstra D, Paradis V, Rugge M, Schirmacher P, et al. The 2019 WHO classification of tumours of the digestive system. Histopathology. 2020;76(2):182-8.

3. Travis WD, Brambilla E, Nicholson AG, Yatabe Y, Austin JHM, Beasley MB, et al. The 2015 World Health Organization Classification of Lung Tumors. J Thorac Oncol. 2015;10(9):1243-60.

4. Hofland J, Kaltsas G, de Herder WW. Advances in the Diagnosis and Management of Well-Differentiated Neuroendocrine Neoplasms. Endocr Rev. 2020;41(2):371-403.

5. Rinke A, Müller H-H, Schade-Brittinger C, Klose K-J, Barth $\mathrm{P}$, Wied M, et al. Placebo-Controlled, Double-Blind, Prospective, Randomized Study on the Effect of Octreotide LAR in the Control of Tumor Growth in Patients With Metastatic Neuroendocrine Midgut Tumors: A Report From the PROMID Study Group. J Clin Oncol. 2009;27:4656-63.

6. Caplin ME, Pavel M, Ćwikła JB, Phan AT, Raderer M, Sedláčková E, et al. Lanreotide in metastatic enteropancreatic neuroendocrine tumors. N Engl J Med. 2014;371(3):224-33.

7. Eric R, Laetitia D, Jean-Luc R, Yung-Jue B, Ivan B, Catherine L-B, et al. Sunitinib Malate for the Treatment of Pancreatic Neuroendocrine Tumors. N Engl J Med. 2011;364:501-13.

8. Yao JC, Shah MH, Tetsuhide I, Catherine L-B, Wolin EM, Cutsem EV. Everolimus for Advanced Pancreatic Neuroendocrine Tumors. N Engl J Med. 2011;364:514-23.

9. Yao JC, Fazio N, Singh S, Buzzoni R, Carnaghi C, Wolin E, et al. Everolimus for the treatment of advanced, non-functional neuroendocrine tumours of the lung or gastrointestinal tract (RADIANT4): a randomised, placebo-controlled, phase 3 study. The Lancet. 2016;387(10022):968-77.

10. Strosberg J, El-Haddad G, Wolin E, Hendifar A, Yao J, Chasen B, et al. Phase 3 Trial of 177Lu-Dotatate for Midgut Neuroendocrine Tumors. N Engl J Med. 2017;376:125-35.

11. Moertel CG, Hanley JA, Johnson LA. Streptozocin Alone Compared with Streptozocin plus Fluorouracil in the Treatment of Advanced Islet-Cell Carcinoma. N Engl J Med. 1980;303(21):1189-94.

12. Moertel C, Lefkopoulo M, Lipsitz S, Hahn R, Klaassen D. Streptozocin-doxorubicin, streptozocin-fluorouracil or chlorozotocin in the treatment of advanced islet-cell carcinoma. $\mathrm{N}$ Engl $\mathrm{J}$ Med. 1992;326(8):519-23.

13. Meyer T, Qian W, Caplin ME, Armstrong G, Lao-Sirieix S-H, Hardy R, et al. Capecitabine and streptozocin \pm cisplatin in advanced gastroenteropancreatic neuroendocrine tumours. Eur J Cancer. 2014;50(5):902-11.

14. Ducreux M, Dahan L, Smith D, O'Toole D, Lepère C, Dromain $\mathrm{C}$, et al. Bevacizumab combined with 5-FU/streptozocin in patients with progressive metastatic well-differentiated pancreatic endocrine tumours (BETTER trial) - A phase II nonrandomised trial. Eur J Cancer. 2014;50(18):3098-106.

15. Ramanathan RK, Cnaan A, Hahn RG, Carbone PP, Haller DG. Phase II trial of dacarbazine (DTIC) in advanced pancreatic islet cell carcinoma. Study of the Eastern Cooperative Oncology Group-E6282. Ann Oncol. 2001;12(8):1139-43.
16. Bajetta E, Ferrari L, Procopio G, Catena L, Ferrario E, Martinetti A, et al. Efficacy of a chemotherapy combination for the treatment of metastatic neuroendocrine tumours. Ann Oncol. 2002;13(4):614-21.

17. Bajetta E, Rimassa L, Carnaghi C, Seregni E, Ferrari L, Bartolomeo MD, et al. 5-fluorouracil, dacarbazine, and epirubicin in the treatment of patients with neuroendocrine tumors. Am Cancer Soc. 1998;83(2):372-8.

18. Kulke MH, Hornick JL, Frauenhoffer C, Hooshmand S, Ryan DP, Enzinger PC, et al. O6-Methylguanine DNA Methyltransferase Deficiency and Response to Temozolomide-Based Therapy in Patients with Neuroendocrine Tumors. Clin Cancer Res. 2009; 15(1):338-45.

19. Cives M, Ghayouri M, Morse B, Brelsford M, Black M, Rizzo A, et al. Analysis of potential response predictors to capecitabine/ temozolomide in metastatic pancreatic neuroendocrine tumors. Endocr Relat Cancer. 2016;23(9):759-67.

20. Kulke MH, Stuart K, Enzinger PC, Ryan DP, Clark JW, Muzikansky A, et al. Phase II Study of Temozolomide and Thalidomide in Patients With Metastatic Neuroendocrine Tumors. J Clin Oncol. 2006;24(3):401-6.

21. Chan JA, Stuart K, Earle CC, Clark JW, Bhargava P, Miksad R, et al. Prospective Study of Bevacizumab Plus Temozolomide in Patients With Advanced Neuroendocrine Tumors. J Clin Oncol. 2012;30(24):2963-8.

22. Chan JA, Blaszkowsky L, Stuart K, Zhu AX, Allen J, Wadlow $\mathrm{R}$, et al. A prospective, phase $1 / 2$ study of everolimus and temozolomide in patients with advanced pancreatic neuroendocrine tumor: Everolimus Temozolomide in Pancreatic NET. Cancer. 2013;119(17):3212-8.

23. Strosberg JR, Fine RL, Choi J, Nasir A, Coppola D, Chen D-T, et al. First-line chemotherapy with capecitabine and temozolomide in patients with metastatic pancreatic endocrine carcinomas. Cancer. 2011;117(2):268-75.

24. Ganetsky A, Adel NG, Do KG, Reidy DL. The efficacy of capecitabine and temozolomide for the treatment of metastatic neuroendocrine tumors: Memorial Sloan-Kettering Cancer Center experience. J Clin Oncol. 2012;30(4_suppl):363-363.

25. Saif MW, Kaley K, Brennan M, Garcon MC, Rodriguez G, Rodriguez T. A Retrospective Study of Capecitabine/Temozolomide (CAPTEM) Regimen in the Treatment of Metastatic Pancreatic Neuroendocrine Tumors (pNETs) after Failing Previous Therapy. J Pancreas Online. 2013;14(5):498-501.

26. Fine RL, Gulati AP, Krantz BA, Moss RA, Schreibman S, Tsushima DA, et al. Capecitabine and temozolomide (CAPTEM) for metastatic, well-differentiated neuroendocrine cancers: The Pancreas Center at Columbia University experience. Cancer Chemother Pharmacol. 2013;71(3):663-70.

27. Abbasi S, Kashashna A, Albaba H. Efficacy of Capecitabine and Temozolomide Combination in Well-Differentiated Neuroendocrine Tumors: Jordan Experience. Pancreas. 2014;43(8):1303-5.

28. Peixoto RD, Noonan KL, Pavlovich P, Kennecke HF, Lim HJ. Outcomes of patients treated with capecitabine and temozolamide for advanced pancreatic neuroendocrine tumors (PNETs) and non-PNETs. J Gastrointest Oncol. 2014;5(4):247-52.

29. Ramirez RA, Beyer DT, Chauhan A, Boudreaux JP, Wang Y, Woltering EA. The Role of Capecitabine/Temozolomide in Metastatic Neuroendocrine Tumors. Oncologist. 2016;21(6):671-5.

30. Crespo G, Jiménez-Fonseca P, Custodio A, López C, CarmonaBayonas A, Alonso V, et al. Capecitabine and temozolomide in grade $1 / 2$ neuroendocrine tumors: a Spanish multicenter experience. Future Oncol. 2017;13(7):615-24.

31. Kunz PL, Catalano PJ, Nimeiri H, Fisher GA, Longacre TA, Suarez CJ, et al. A randomized study of temozolomide or temozolomide and capecitabine in patients with advanced 
pancreatic neuroendocrine tumors: A trial of the ECOGACRIN Cancer Research Group (E2211). J Clin Oncol. 2018;36(15_suppl):4004-4004.

32. Chatzellis E, Angelousi A, Daskalakis K, Tsoli M, Alexandraki KI, Wachuła E, et al. Activity and Safety of Standard and Prolonged Capecitabine/Temozolomide Administration in Patients with Advanced Neuroendocrine Neoplasms. Neuroendocrinology. 2019;109(4):333-45.

33. Lamarca A, Barriuso J, McNamara MG, Hubner RA, Manoharan $\mathrm{P}$, Mansoor W, et al. Temozolomide-Capecitabine Chemotherapy for Neuroendocrine Neoplasms: The Dilemma of Treatment Duration. Neuroendocrinology. 2020;110:155-7.

34. Claringbold PG, Price RA, Turner JH. Phase I-II Study of Radiopeptide 177Lu-Octreotate in Combination with Capecitabine and Temozolomide in Advanced Low-Grade Neuroendocrine Tumors. Cancer Biother Radiopharm. 2012;27(9):561-9.

35. Claringbold PG, Turner JH. Pancreatic Neuroendocrine Tumor Control: Durable Objective Response to Combination 177LuOctreotate-Capecitabine-Temozolomide Radiopeptide Chemotherapy. Neuroendocrinology. 2016;103(5):432-9.

36. Pavlakis N, Ransom D, Wyld D, Sjoquist K, Asher R, Gebski V, et al. Australasian Gastrointestinal Trials Group (AGITG) CONTROL NET Study: Phase II study evaluating the activity of $177 \mathrm{Lu}$-Octreotate peptide receptor radionuclide therapy (LuTate PRRT) and capecitabine, temozolomide CAPTEM)—First results for pancreas and updated midgut neuroendocrine tumors (pNETS, mNETS). J Clin Oncol. 2020;38(15_suppl):4608-4608.

37. Uboha NV, Lubner SJ, LoConte NK, Mulkerin DL, Eickhoff JC, Deming DA. Phase 1 dose escalation trial of TAS-102 (trifluridine/tipiracil) and temozolomide in the treatment of advanced neuroendocrine tumors. Invest New Drugs. 2020;38(5):1520-5.

38. Brixi-Benmansour H, Jouve J-L, Mitry E, Bonnetain F, Landi $\mathrm{B}$, Hentic O, et al. Phase II study of first-line FOLFIRI for progressive metastatic well-differentiated pancreatic endocrine carcinoma. Dig Liver Dis. 2011;43(11):912-6.

39. Ducreux MP, Boige V, Leboulleux S, Malka D, Kergoat P, Dromain C, et al. A Phase II Study of Irinotecan with 5-Fluorouracil and Leucovorin in Patients with Pretreated Gastroenteropancreatic Well-Differentiated Endocrine Carcinomas. Oncology. 2006;70(2):134-40.

40. Spada F, Antonuzzo L, Marconcini R, Radice D, Antonuzzo A, Ricci S, et al. Oxaliplatin-Based Chemotherapy in Advanced Neuroendocrine Tumors: Clinical Outcomes and Preliminary Correlation with Biological Factors. Neuroendocrinology. 2016;103(6):806-14.

41. Moertel CG, Kvols LK, O'Connell MJ, Rubin J. Treatment of neuroendocrine carcinomas with combined etoposide and cisplatin. Evidence of major therapeutic activity in the anaplastic variants of these neoplasms. Cancer. 1991;68(2):227-32.

42. Fjällskog ML, Granberg DP, Welin SL, Eriksson C, Oberg KE, Janson ET, Eriksson BK. Treatment with cisplatin and etoposide in patients withneuroendocrine tumors. Cancer. 2001;92(5):1101-7.

43. Bajetta E, Catena L, Procopio G, De Dosso S, Bichisao E, Ferrari $\mathrm{L}$, et al. Are capecitabine and oxaliplatin (XELOX) suitable treatments for progressing low-grade and high-grade neuroendocrine tumours? Cancer Chemother Pharmacol. 2007;59(5):637-42.

44. Kunz PL, Balise RR, Fehrenbacher L, Pan M, Venook AP, Fisher GA, et al. Oxaliplatin-Fluoropyrimidine Chemotherapy Plus Bevacizumab in Advanced Neuroendocrine Tumors: An Analysis of 2 Phase II Trials. Pancreas. 2016;45(10):1394-400.

45. Grande E, Lopez C, Alonso Gordoa T, Benavent M, Capdevila J, Teulé A, et al. SUNitinib with EVOfosfamide (TH-302) for G1/G2 metastatic pancreatic neuroendocrine tumours (pNETs) naïve for systemic treatment. The SUNEVO phase II trial of the Spanish task force group for neuroendocrine and endocrine tumours (GETNE). Ann Oncol. 2019;30:v566.

46. Randomized Phase 2 Trial Of Two Chemotherapy Regimens Plus Or Minus Bevacizumab In Patients With Well Differentiated Pancreatic Neuroendocrine Tumors (NCT03351296). Available from: https://clinicaltrials.gov.

47. Randomized Open Label Study to Compare the Efficacy and Safety of Everolimus Followed by Chemotherapy With StreptozotocinFluorouracilo (STZ-5FU) Upon Progression or the Reverse Sequence, in Advanced Progressive Pancreatic NETs (pNETs) (NCT02246127). Available from: https://clinicaltrials.gov.

48. Antitumor Efficacy of Peptide Receptor Radionuclide Therapy With 177Lutetium -Octreotate Randomized vs Sunitinib in Unresectable Progressive Well-differentiated Neuroendocrine Pancreatic Tumor: First Randomized Phase II (NCT02230176). Available from: https://clinicaltrials.gov.

49. A Prospective, Randomised, Controlled, Open-label, Multicentre Phase III Study to Evaluate Efficacy and Safety of Peptide Receptor Radionuclide Therapy (PRRT) With 177Lu-Edotreotide Compared to Targeted Molecular Therapy With Everolimus in Patients With Inoperable, Progressive, Somatostatin Receptor-positive (SSTR+), Neuroendocrine Tumours of Gastroenteric or Pancreatic Origin (GEP-NET) (NCT03049189). Available from: https://clinicaltrials.gov.

50. Fine RL, Gulati AP, Tsushima D, Mowatt KB, Oprescu A, Bruce JN, et al. Prospective phase II study of capecitabine and temozolomide (CAPTEM) for progressive, moderately, and well-differentiated metastatic neuroendocrine tumors. J Clin Oncol. 2014;32(3_suppl):179-179.

51. Berruti A, Fazio N, Ferrero A, Brizzi MP, Volante M, Nobili E, et al. Bevacizumab plus octreotide and metronomic capecitabine in patients with metastatic well-to-moderately differentiated neuroendocrine tumors: the xelbevoct study. BMC Cancer. 2014;14(1):184.

52. Moertel C, Hanley JA. Combination chemotherapy trials in metastatic carcinoid tumor and the malignant carcinoid syndrome. Cancer Clin Trials. 1979;2(4):327-34.

53. Engstrom PF, Lavin PT, Folsch E, Douglass HO. Streptozocin plus Fluorouracil versus Doxorubicin therapy for metastatic carcinoid tumor. J Clin Oncol. 1984;2(11):1255-9.

54. Sun W, Lipsitz S, Catalano P, Mailliard JA, Haller DG. Phase II/III Study of Doxorubicin With Fluorouracil Compared With Streptozocin With Fluorouracil or Dacarbazine in the Treatment of Advanced Carcinoid Tumors: Eastern Cooperative Oncology Group Study E1281. J Clin Oncol. 2005;23(22):4897-904.

55. Dahan L, Bonnetain F, Rougier P, Raoul J-L, Gamelin E, Etienne P-L, et al. Phase III trial of chemotherapy using 5-fluorouracil and streptozotocin compared with interferon a for advanced carcinoid tumors: FNCLCC-FFCD 9710. Endocr Relat Cancer. 2009;16:1351-61.

56. Bukowski R, Tangen C, Peterson R, Taylor S, Rinehart J, Eyre $\mathrm{H}$, et al. Phase II trial of dimethyltriazenoimidazole carboxamide in patients with metastatic carcinoid. A Southwest Oncology Group study Cancer. 1994;73(5):1505-8.

57. Turner NC, Strauss SJ, Sarker D, Gillmore R, Kirkwood A, Hackshaw A, et al. Chemotherapy with 5-fluorouracil, cisplatin and streptozocin for neuroendocrine tumours. Br J Cancer. 2010;102(7):1106-12.

58. Medley L, Morel AN, Farrugia D, Reed N, Hayward N, Davies JM, et al. Phase II study of single agent capecitabine in the treatment of metastatic non-pancreatic neuroendocrine tumours. Br J Cancer. 2011;104(7):1067-70.

59. Mitry E, Walter T, Baudin E, Kurtz J-E, Ruszniewski P, DominguezTinajero $\mathrm{S}$, et al. Bevacizumab plus capecitabine in patients with progressive advanced well-differentiated neuroendocrine tumors of the gastro-intestinal (GI-NETs) tract (BETTER trial) - A phase II non-randomised trial. Eur J Cancer. 2014;50(18):3107-15. 
60. Ekeblad S, Sundin A, Janson ET, Welin S, Granberg D, Kindmark $\mathrm{H}$, et al. Temozolomide as Monotherapy Is Effective in Treatment of Advanced Malignant Neuroendocrine Tumors. Clin Cancer Res. 2007;13(10):2986-91.

61. Ferrolla P, Berruti A, Spada F, Brizzi MP, Ibrahim T, Colao A, et al. Lanreotide autogel (LAN) and temozolomide (TMZ) combination therapy in progressive thoracic neuroendocrine tumours (TNETs): ATLANT study results. Ann Oncol 2020 31 Supp14 S711-S724 101016/annonc/annonc281.

62. Papaxoinis G, Kordatou Z, McCallum L, Nasralla M, Lamarca A, Backen A, et al. Capecitabine and Temozolomide in Patients with Advanced Pulmonary Carcinoid Tumours. Neuroendocrinology. 2020;110(5):413-421; Al-Toubah T, Morse B, Strosberg J. Capecitabine and Temozolomide in Advanced Lung Neuroendocrine Neoplasms. Oncologist. 2020;25(1):e48-e52. https:// doi.org/10.1634/theoncologist.2019-0361. Epub 2019 Aug 27

63. Granberg D, Eriksson B, Wilander E, Grimfjärd P, Fjällskog M-L, Öberg K, et al. Experience in treatment of metastatic pulmonary carcinoid tumors. Ann Oncol. 2001;12(10):1383-91.

64. Forde PM, Hooker CM, Boikos SA, Petrini I, Giaccone G, Rudin $\mathrm{CM}$, et al. Systemic Therapy, Clinical Outcomes, and Overall Survival in Locally Advanced or Metastatic Pulmonary Carcinoid: A Brief Report. J Thorac Oncol. 2014;9(3):414-8.

65. Chong CR, Wirth LJ, Nishino M, Chen AB, Sholl LM, Kulke $\mathrm{MH}$, et al. Chemotherapy for locally advanced and metastatic pulmonary carcinoid tumors. Lung Cancer. 2014;86(2):241-6.

66. Lamarca A, Elliott E, Barriuso J, Backen A, McNamara MG, Hubner R, et al. Chemotherapy for advanced non-pancreatic well-differentiated neuroendocrine tumours of the gastrointestinal tract, a systematic review and meta-analysis: A lost cause? Cancer Treat Rev. 2016;44:26-41.

67. Garcia-Carbonero R, Sorbye H, Baudin E, Raymond E, Wiedenmann B, Niederle B, et al. ENETS Consensus Guidelines for High-Grade Gastroenteropancreatic Neuroendocrine Tumors and Neuroendocrine Carcinomas. Neuroendocrinology. 2016;103(2):186-94.

68. Garcia-Carbonero R, Rinke A, Valle JW, Fazio N, Caplin M, Gorbounova $\mathrm{V}$, et al. ENETS Consensus Guidelines for the Standards of Care in Neuroendocrine Neoplasms: Systemic Therapy - Chemotherapy. Neuroendocrinology. 2017;105(3):281-94.

69. Sorbye H, Welin S, Langer SW, Vestermark LW, Holt N, Osterlund $\mathrm{P}$, et al. Predictive and prognostic factors for treatment and survival in 305 patients with advanced gastrointestinal neuroendocrine carcinoma (WHO G3): The NORDIC NEC study. Ann Oncol. 2013;24(1):152-60.

70. Mitry E, Baudin E, Ducreux M, Sabourin J-C, Rufié P, Aparicio T, et al. Treatment of poorly differentiated neuroendocrine tumours with etoposide and cisplatin. Br J Cancer. 1999;81(8):1351-5.

71. Iwasa S, Morizane C, Okusaka T, Ueno H, Ikeda M, Kondo S, et al. Cisplatin and Etoposide as First-line Chemotherapy for Poorly Differentiated Neuroendocrine Carcinoma of the Hepatobiliary Tract and Pancreas. Jpn J Clin Oncol. 2010;40(4):313-8.

72. Deutschbein T, Unger N, Yuece A, Eberhardt W, Gauler T, Lahner $\mathrm{H}$, et al. Chemotherapy in Patients with Progressive, Undifferentiated Neuroendocrine Tumors: A Single-Center Experience. Horm Metab Res. 2011;43(12):838-43.

73. Patta A, Fakih M. First-line Cisplatin Plus Etoposide in Highgrade Metastatic Neuroendocrine Tumors of Colon and Rectum (MCRC NET): Review of 8 Cases. ANTICANCER Res. 2011;975-978.

74. Yamaguchi T, Machida N, Morizane C, Kasuga A, Takahashi $\mathrm{H}$, Sudo K, et al. Multicenter retrospective analysis of systemic chemotherapy for advanced neuroendocrine carcinoma of the digestive system. Cancer Sci. 2014;105(9):1176-81.

75. Walter T, Tougeron D, Baudin E, Le Malicot K, Lecomte T, Malka D, et al. Poorly differentiated gastro-entero-pancreatic neuroendocrine carcinomas: Are they really heterogeneous? Insights from the FFCD-GTE national cohort. Eur J Cancer. 2017;79:158-65.

76. Frizziero M, Spada F, Lamarca A, Kordatou Z, Barriuso J, Nuttall $\mathrm{C}$, et al. Carboplatin in Combination with Oral or Intravenous Etoposide for Extra-Pulmonary. Poorly-Differentiated Neuroendocrine Carcinomas Neuroendocrinology. 2019;109(2):100-12.

77. Alese OB, Jiang R, Shaib W, Wu C, Akce M, Behera M, et al. High-Grade Gastrointestinal Neuroendocrine Carcinoma Management and Outcomes: A National Cancer Database Study. Oncologist. 2020;25(5): e877.

78. Jimenez-Fonseca P, La Salvia A, Capdevila J, Castaño A, Benavent M, Alonso-Orduña V, et al. Survival and prognostic factors analysis of 535 grade 3 gastroenteropancreatic neuroendocrine neoplasm (GEP-NEN): Data from the Spanish Taskforce of Neuroendocrine Tumours Registry (R-GETNE). Ann Oncol 202031 Suppl4 S711-S724 101016/annonc/annonc281.

79. Hainsworth JD, Spigel DR, Litchy S, Greco FA. Phase II Trial of Paclitaxel, Carboplatin, and Etoposide in Advanced Poorly Differentiated Neuroendocrine Carcinoma: A Minnie Pearl Cancer Research Network Study. J Clin Oncol. 2006;24(22):3548-54.

80. A Phase II Study of Platinum-doublet Chemotherapy in Combination With Nivolumab as First-line Treatment in Subjects With Unresectable, Locally Advanced or Metastatic G3 Neuroendocrine Neoplasms (NENs) of the Gastroenteropancreatic (GEP) Tract or of Unknown (UK) Origin. (NCT03980925). Available from: https://clinicaltrials.gov.

81. Ramella Munhoz R, de Mendonça Rego JF, de Celis Ferrari AR, Ignez Braghiroli M, Mendonça Bariani G, Hoff PM, et al. Combination of Irinotecan and a Platinum Agent for Poorly Differentiated Neuroendocrine Carcinomas. Rare tumors. 2013;5(3):135-9.

82. Okita NT, Kato K, Takahari D, Hirashima Y, Nakajima TE, Matsubara J, et al. Neuroendocrine tumors of the stomach: chemotherapy with cisplatin plus irinotecan is effective for gastric poorlydifferentiated neuroendocrine carcinoma. Gastric Cancer. 2011;14(2):161-5.

83. Okuma HS, Iwasa S, Shoji H, Takashima A, Okita N, Honma Y, et al. Irinotecan plus Cisplatin in Patients with Extensive-Disease Poorly Differentiated Neuroendocrine Carcinoma of the Esophagus. ANTICANCER Res. 2014;34:5037-42.

84. Nakano K, Takahashi S, Yuasa T, Nishimura N, Mishima Y, Sakajiri S, et al. Feasibility and Efficacy of Combined Cisplatin and Irinotecan Chemotherapy for Poorly Differentiated Neuroendocrine Carcinomas. Jpn J Clin Oncol. 2012;42(8):697-703.

85. Lu ZH, Li J, Lu M, Zhang XT, Li J, Zhou J, et al. Feasibility and efficacy of combined cisplatin plus irinotecan chemotherapy for gastroenteropancreatic neuroendocrine carcinomas. Med Oncol. 2013;30(3):664

86. Mani MA, Shroff RT, Jacobs C, Wolff RA, Ajani JA, Yao JC, et al. A phase II study of irinotecan and cisplatin for metastatic or unresectable high grade neuroendocrine carcinoma. J Clin Oncol. 2008;26(15_suppl):15550-15550.

87. A Randomized, Controlled Phase II Study to Compare Irinotecan Combined With Cisplatin (IP) Versus Etoposide Combined With Cisplatin (EP) in Advanced and Metastatic Gastrointestinal Pancreatic and Esophageal Neuroendocrine Carcinoma. (NCT03168594) Available from: https://clinicaltrials.gov.

88. ECOG-ACRIN Cancer Research Group. Randomized Phase II Study of Cisplatin and Etoposide Versus Temozolomide and Capecitabine in Patients With Advanced G3 Non-small Cell Gastroenteropancreatic Neuroendocrine Carcinomas (NCT02595424). Available from: https://clinicaltrials.gov.

89. Alifieris CE, Griniatsos J, Delis SG, Nikolaou M, Avgoustou C, Panagiotidis MI, et al. Capecitabine, Oxaliplatin, Irinotecan, and Bevacizumab Combination Followed by Pazopanib Plus 
Capecitabine Maintenance for High-Grade Gastrointestinal Neuroendocrine Carcinomas. Am J Clin Oncol. 2020;43(5):305-10.

90. Hentic O, Hammel P, Couvelard A, Rebours V, Zappa M, Palazzo $M$, et al. FOLFIRI regimen: an effective second-line chemotherapy after failure of etoposide-platinum combination in patients with neuroendocrine carcinomas grade 3 . Endocr Relat Cancer. 2012;19(6):751-7.

91. Ferrarotto R, Testa L, Riechelmann RP, Sahade M, Siqueira LT, Costa FP, et al. Combination of Capecitabine and Oxaliplatin is an Effective Treatment Option for Advanced Neuroendocrine Tumors. Rare Tumors. 2013;5(3):121-5.

92. Hadoux J, Malka D, Planchard D, Scoazec JY, Caramella C, Guigay J, et al. Post-first-line FOLFOX chemotherapy for grade 3 neuroendocrine carcinoma. Endocr Relat Cancer. 2015;22(3):289-98.

93. Welin S, Sorbye H, Sebjornsen S, Knappskog S, Busch C, Öberg K. Clinical effect of temozolomide-based chemotherapy in poorly differentiated endocrine carcinoma after progression on first-line chemotherapy. Cancer. 2011;117(20):4617-22.

94. Olsen IH, Sørensen JB, Federspiel B, Kjaer A, Hansen CP, Knigge U, et al. Temozolomide as Second or Third Line Treatment of Patients with Neuroendocrine Carcinomas. Sci World J. 2012;2012:1-4

95. Kobayashi N, Takeda Y, Okubo N, Suzuki A, Tokuhisa M, Hiroshima Y, Ichikawa Y. Phase II study of temozolomide monotherapy in patients with extrapulmonary neuroendocrine carcinoma. Cancer Sci. 2021 Jan 16. https://doi.org/10.1111/cas.14811. Epub ahead of print. PMID: 33453146.

96. McNamara MG, Frizziero M, Jacobs T, Lamarca A, Hubner RA, Valle JW, et al. Second-line treatment in patients with advanced extra-pulmonary poorly differentiated neuroendocrine carcinoma: a systematic review and meta-analysis. Ther Adv Med Oncol. 2020;12:1-14.

97. A Randomized Phase II Trial of Capecitabine and Temozolomide (CAPTEM) or FOLFIRI as SEcond-line Therapy in NEuroendocrine CArcinomas and Exploratory Analysis of Predictive Role of Positron Emission Tomography (PET) Imaging and Biological Markers (NCT03387592). Available from: https://clinicaltrials. gov.

98. Assessment of the Efficacy of Bevacizumab in Combination With Folfiri as Second-line Treatment After the Failure of the Cisplatin (or Carboplatin)-Etoposide Combination in Patients Suffering From an Advanced Inoperable Poorly Differentiated Neuroendocrine Carcinoma of an Unknown or Gastroentero-pancreatic Primary Cancer. A Phase 2 Non-comparative Randomized Study (NCT02820857). Available from: https://clinicaltrials.gov.

99. Craig Z, Swain J, Batman E, Wadsley J, Reed N, Faluyi O, et al. NET-02 trial protocol: a multicentre, randomised, parallel group, open-label, phase II, single-stage selection trial of liposomal irinotecan (nal-IRI) and 5-fluorouracil (5-FU)/folinic acid or docetaxel as second-line therapy in patients with progressive poorly differentiated extrapulmonary neuroendocrine carcinoma (NEC). BMJ Open. 2020;10(2):e034527.

100. Jimenez-Fonseca P, Alonso V, Hernando J, Lopez C, La Salvia A, Crespo G, et al. Análisis de supervivencia y factores pronósticos en carcinomas neuroendocrinos gastroenteropancreáticos: datos de 601 pacientes de resgistro R-GETNE. Libro Comun Congr Virtual SEOM 2020. ePóster 443:488-9.

101. NCCN Clinical practice guidelines in oncology. Neuroendocrine and adrenal tumors, version 2. 2020. Available at: https://nccn. org.

102. Caplin ME, Baudin E, Ferolla P, Filosso P, Garcia-Yuste M, Lim E, et al. Pulmonary neuroendocrine (carcinoid) tumors: European Neuroendocrine Tumor Society expert consensus and recommendations for best practice for typical and atypical pulmonary carcinoids. Ann Oncol. 2015;26(8):1604-20.
103. Kunz PL, Reidy-Lagunes D, Anthony LB, Bertino EM, Bredtro K, Chan JA, et al. Consensus Guidelines for the management and treatment of neuroendocrine tumors. Pancreas. 2013;42(4):557-77.

104. Baudin E, Caplin M, Garcia-Carbonero R, Fazio N, Ferolla P, Filosso PL, et al. ESMO Guidelines Committee. Lung and thymic carcinoids: ESMO Clinical Practice Guidelines for diagnosis, treatment and follow-up. Ann Oncol. 2021:S0923-7534(21)00011-9.

105. Nussbaum DP, Speicher PJ, Gulack BC, Hartwig MG, Onaitis MW, D'Amico TA, et al. Defining the Role of Adjuvant Chemotherapy After Lobectomy for Typical Bronchopulmonary Carcinoid Tumors. Ann Thorac Surg. 2015;99(2):428-34.

106. Marcondes W, Samer A, Konstatinos L, Ragnar H, R M. Impact of adjuvant chemotherapy in non-metastatic node positive bronchial neuroendocrine tumors (BNET). J Clin Oncol. 2017;35(15_suppl):8533-8533.

107. Westin G, Alsidawi S, Leventakos K, Halfdanarson T, Molina $\mathrm{J}$. Impact of adjuvant chemotherapy in non-metastatic node positive bronchial neuroendocrine tumors (BNET). J Clin Oncol. 2017;35(15_suppl):8533-8533.

108. Steuer CE, Behera M, Kim S, et al. Atypical carcinoid tumor of the lung: a surveillance, epidemiology, and end results database analysis. J Thorac Oncol. 2015;10:479-85.

109. Anderson KL, Mulvihill MS, Speicher PJ, et al. Adjuvant Chemotherapy Does Not Confer Superior Survival in Patients With Atypical Carcinoid Tumors. Ann Thorac Surg. 2017;104:1221-30.

110. Daddi N, Schiavon M, Filosso PL, et al. Multi-Institutional Italian Pathology Group: Prognostic factors in a multicentre study of 247 atypical pulmonary carcinoids. Eur J Cardiothorac Surg. 2014;45:677-86.

111. Gaur P, Leary C, Yao JC et al. Thymic neuroendocrine tumors: a SEER database analysis of 160 patients. Ann. Surg. 2010;251:1117-1121.

112. Filosso PL, Yao X, Ahmad U, et al. Outcome of primary neuroendocrine tumors of the thymus: a joint analysis of the International Thymic Malignancy Interest Group and the European Society of Thoracic Surgeons databases. J Thorac Cardiovasc Surg. 2015;149:103-9.

113. Sullivan JL, Weksler B. Neuroendocrine Tumors of the Thymus: Analysis of Factors Affecting Survival in 254 Patients. Ann Thorac Surg. 2017;103:935-9.

114. Zhao Y, Gu H, Fan L, et al. Comparison of clinical features and survival between thymic carcinoma and thymic carcinoid patients. Eur J Cardiothorac Surg. 2017;52:33-8.

115. Pavel M, O' Toole D, Costa F, Capdevila J, Gross D, Kianmanesh $\mathrm{R}$, et al. ENETS Consensus Guidelines Update for the Management of Distant Metastatic Disease of Intestinal, Pancreatic, Bronchial Neuroendocrine Neoplasms (NEN) and NEN of Unknown Primary Site. Neuroendocrinology. 2016;103(2):172-85.

116. Pavel M, Öberg K, Falconi M, Krenning EP, Sundin A, Perren A, et al. Gastroenteropancreatic neuroendocrine neoplasms: ESMO Clinical Practice Guidelines for diagnosis, treatment and followup. Ann Oncol. 2020;31(7):844-60.

117. Nordic and Childs A, Kirkwood A, Edeline J, Luong TV, Watkins $\mathrm{J}$, Lamarca A, et al. Ki-67 index and response to chemotherapy in patients with neuroendocrine tumours. Endocr Relat Cancer. 2016;23(7):563-70.

118. Hijioka S, Hosoda W, Matsuo K, Ueno M, Furukawa M, Yoshitomi H, et al. Rb Loss and KRAS Mutation Are Predictors of the Response to Platinum-Based Chemotherapy in Pancreatic Neuroendocrine Neoplasm with Grade 3: A Japanese Multicenter Pancreatic NEN-G3 Study. Clin Cancer Res. 2017;23(16):4625-32. 
119. Pilié PG, Tang C, Mills GB, Yap TA. State-of-the-art strategies for targeting the DNA damage response in cancer. Nat Rev Clin Oncol. 2019;16(2):81-104.

120. Hegi ME, Diserens AC, Gorlia T, Hamou MF, de tribolet N, Weller M, et al. MGMT gene silencing and benefit from temozolomide in glioblastoma. N Engl J Med. 2005;352(10):997-1003.

121. de Mestier L, Couvelard A, Blazevic A, Hentic O, de Herder WW, Rebours V, et al. Critical appraisal of MGMT in digestive NET treated with alkylating agents. Endocrine-Related Cancer. 2020;27(10):R391-405.

122. Korse CM, Taal BG, van Velthuysen ML, Visser O. Incidence and survival of neuroendocrine tumours in the Netherlands according to histological grade: experience of two decades of cancer registry. Eur J Cancer. 2013;49(8):1975-83.

123. Rekhtman N, Pietanza MC, Hellmann MD, Naidoo J, Arora A, Won $\mathrm{H}$, et al. Next-Generation Sequencing of Pulmonary Large Cell Neuroendocrine Carcinoma Reveals Small Cell Carcinomalike and Non-Small Cell Carcinoma-like Subsets. Clin Cancer Res. 2016;22(14):3618-29.

124. Capdevila J, Arqués O, Hernández Mora JR, Matito J, Caratù G, Mancuso FM, et al. Epigenetic EGFR Gene Repression Confers Sensitivity to Therapeutic BRAFV600E Blockade in Colon Neuroendocrine Carcinomas. Clin Cancer Res. 2020;26(4):902-909.

125. Klempner SJ, Gershenhorn B, Tran P, Lee TK, Erlander MG, Gowen K, et al. BRAFV600E Mutations in High-Grade Colorectal Neuroendocrine Tumors May Predict Responsiveness to BRAF-MEK Combination Therapy. Cancer Discov. 2016;6(6):594-600.

126. Sahnane N, Furlan D, Monti M, Romualdi C, Vanoli A, Vicari E, et al. Microsatellite unstable gastrointestinal neuroendocrine carcinomas: a new clinicopathologic entity. Endocr Relat Cancer. 2015;22(1):35-45.

127. Lemery S, Keegan P, Pazdur R. First FDA Approval Agnostic of Cancer Site - When a Biomarker Defines the Indication. N Engl J Med. 2017;377(15):1409-12.

128. Huang FW, Feng FY. A Tumor-Agnostic NTRK (TRK) Inhibitor. Cell. 2019;177(1):8.

129. FDA Approves Entrectinib for NTRK-Fusion Cancers, ROS1Positive NSCLC - The ASCO Post 2020. Available at: https:// www.ascopost.com/News/60351.

130. Marabelle A, Fakih M, Lopez J, Shah M, Shapira-Frommer R, Nakagawa K, et al. Association of tumour mutational burden with outcomes in patients with select advanced solid tumors treated with pembrolizumab: prospective biomarker analysis of the multicohort, open-label, phase 2 KEYNOTE-158 study. Lancet Oncol. 2020;21(10):1353-65.

Publisher's Note Springer Nature remains neutral with regard to jurisdictional claims in published maps and institutional affiliations. 